\title{
Delapparentia turolensis nov. gen et sp., un nuevo dinosaurio iguanodontoideo (Ornithischia: Ornithopoda) en el Cretácico Inferior de Galve
}

\author{
Delapparentia turolensis nov. gen et sp., a new iguanodontoid dinosaur \\ (Ornithischia: Ornithopoda) from the Lower Cretaceous of Galve \\ (Spain)
}

\author{
J.I. Ruiz-Omeñaca1, 2
}

RESUMEN

Se redescribe un esqueleto postcraneal de dinosaurio ornitópodo asignado por Albert de Lapparent en 1960 a Iguanodon bernissartensis. Procede del yacimiento de La Maca 3, de edad Barremiense inferior (Formación Camarillas), y consta de varias vértebras cervicales, restos de la serie dorsal y sacra, varias vértebras caudales, fragmentos de costillas cervicales, dorsales, y esternales, chevrones y tendones osificados, y la hemipelvis izquierda incompleta. Se ha identificado como un «iguanodóntido» (i.e. un Iguanodontoidea no Hadrosauridae) por la presencia de una lámina prepubica alta y la ausencia de antitrocánter en el ilion. Se propone a partir de este material un nuevo taxón de iguanodontoideo, Delapparentia turolensis nov. gen et sp., caracterizado por las siguientes autapomorfías: 1) costillas dorsales posteriores con capítulo y tubérculo no fusionados, 2) costillas esternales osificadas, y 3) ilion con el proceso preacetabular torsionado y expandido lateromedialmente (compartida con Zalmoxes). Además presenta una combinación de costillas dorsales anteriores con un foramen neumático, e isquion grande en relación al ilion.

Palabras clave: Dinosauria, Iguanodontoidea, esqueleto postcraneal, Barremiense inferior, Teruel, Lapparent

\begin{abstract}
An ornithopod dinosaur postcranial skeleton from the Early Cretaceous of Galve (Teruel province, Spain), assigned to Iguanodon bernissartensis by the French paleontologist Albert de Lapparent in 1960, is redescribed. It comes from La Maca 3 locality, early Barremian in age (Camarillas Formation) and it is made of several cervical vertebrae, fragmentary remains of the dorsal and sacral series, several caudal vertebrae, fragments of cervical, dorsal and sternal ribs, fragments of chevrons and ossified tendons, and an incomplete left hip. It has been identified as an «iguanodontid» (i.e., a non-hadrosaurid iguanodontoid) by the presence of a deep prepubic blade and the absence of antitrochanter on ilium. The skeleton represents a new iguanodontoid taxon, Delapparentia turolensis nov. gen et sp., characterized by the following autapomorphies: 1) posterior dorsal ribs with long, parallel and unfused capitulum and tuberculum, 2) ossified sternal ribs, and 3) straight and lateromedially expanded preacetabular process of ilium (convergent in Zalmoxes). It also presents a combination of anterior dorsal ribs with a pneumatic foramen, and a ischium of big size in relation to ilium.
\end{abstract}

Key words: Dinosauria, Iguanodontoidea, postcranial skeleton, lower Barremian, Teruel province, Lapparent

\footnotetext{
1 Museo del Jurásico de Asturias (MUJA), E-33328 Colunga, España. www.dinoastur.com, email: jigruiz@ unizar.es

2 Grupo Aragosaurus-IUCA, Paleontología, Facultad de Ciencias, Universidad de Zaragoza, Pedro Cerbuna 12, E-50009 Zaragoza, España. www.aragosaurus.com
} 


\section{Introducción}

Los iguanodontoideos son dinosaurios ornitópodos de tamaño mediano a grande, herbívoros y bípedos facultativos. En Europa se han descrito siete géneros en el Cretácico Inferior: Iguanodon Mantell 1825 en Alemania, Bélgica, España, Francia y Reino Unido, Mantellisaurus PAUL 2007 en el Reino Unido y quizás Alemania, Dollodon PAUL 2008 en Bélgica y posiblemente Alemania y Reino Unido, y, muy recientemente, Owenodon Galton 2009, Barilium Norman 2010, Hypselospinus Norman 2010 y Kukufeldia McDonald, BARRETT et CHAPMAN 2010 en el Reino Unido (Norman 2004; Weishampel et al., 2004; Paul, 2007, 2008; Galton, 2009; Norman, 2010, McDonald et al., 2010).

En España se han descrito restos asignados a Iguanodon, en las provincias de Burgos, Castellón, Cuenca, Soria y Teruel (véanse Ruiz-Omeñaca et $a l ., 1998$ y Ruiz-Omeñaca \& Canudo, 2004 y referencias; Fuentes Vidarte et al., 2005). Más recientemente, nuevos restos descubiertos se están describiendo como «Iguanodontidae» indet. o Iguanodontoidea indet. (por ejemplo: Torcida Fernández-Baldor et al., 2006; Contreras-Izquierdo et al., 2009; Ruiz-Omeñaca et al., 2009).

La única especie de Iguanodon confirmada en España es I. bernissartensis BoULENGER 1881 en el Aptiense de Morella (Castellón, Sanz et al., 1982; Gasulla et al., 2009). Los restos de I. cf. fittoni del Cretácico Inferior de Salas de los Infantes (Burgos, Maisch, 1997) han sido recientemente asignados a Iguanodontoidea indet. (Torcida Fernández-Baldor et al., 2008).

Aunque se ha citado I. atherfieldensis HoOLEY 1925 [= Mantellisaurus atherfieldensis según Paul, 2007] en varias localidades españolas (provincias de Burgos, Castellón y Teruel; véanse referencias en Ruiz-Omeñaca et al., 1998), según Ruiz-Omeñaca et al. (1998) las asignaciones se hicieron basándose sólo en el tamaño relativamente pequeño y no en caracteres diagnósticos, por lo que únicamente la presencia de I. cf atherfieldensis parecía estar probada en el yacimiento turolense de San Cristóbal (Galve; restos descritos y figurados por Sanz et al., 1984: láms. 1 y 2 como I. bernissartensis [fragmento de dentario derecho] e $I$. cf. mantelli [fragmento de neurocráneo, atlas y fragmento de dentario izquierdo]. Ruiz-Omeñaca (2006: 222) asignó todos los restos de San Cristóbal, que consideró podían pertenecer a un mismo individuo, a I. cf atherfiel- densis, aunque notando también semejanzas con Ouranosaurus nigeriesis TAQUET 1976. No obstante, las descripciones clásicas del cráneo de $I$. atherfieldensis de Norman (1986) se basan en dos ejemplares: NHMUK R5764 (holotipo de I. atherfieldensis, procedente de Inglaterra) e IRSNB 1551 (recientemente designado el holotipo de Dollodon bambingi Paul 2008, procedente de Bélgica; Paul, 2008), por lo que hasta que no se reestudien en detalle los cráneos de estas dos especies, las comparaciones de los restos de Galve con Mantellisaurus y Dollodon no son posibles, y la presencia de Mantellisaurus atherfieldensis (HOOLEy 1925) en el Cretácico Inferior de Teruel es problemática [Nótese aquí que los géneros Dollodon y Mantellisaurus y la especie $D$. bambingi no son citados en un reciente trabajo que menciona los restos de iguanodontoideos de Bélgica (Godefroit, 2009), y que algunos trabajos recientes no tienen en cuenta las publicaciones de Paul $(2007,2008)$ porque este autor no ha examinado los materiales originales de sus nuevos taxones (e.g. Knoll, 2009: 758)].

En este trabajo se redescriben los restos postcraneales del yacimiento de «La Maca» (rebautizado como La Maca 3, Ruiz-Omeñaca et al., 2004a), en Galve (Teruel), que fueron descritos hace cincuenta años por Lapparent (1960) como Iguanodon bernissartensis (véase historia del descubrimiento en Alcalá, 2005 y Ruiz-Omeñaca, 2006), demostrando que no pertenecen a esa forma sino a un nuevo género y especie de iguanodontoideo, hipótesis ya propuesta por Ruiz-Omeñaca et al. (2003, 2004b, 2004c) y Ruiz-Omeñaca (2006).

\footnotetext{
Abreviaturas institucionales. FCPT-D: Museo de la Fundación Conjunto Paleontológico de Teruel-Dinópolis, Teruel; IRSNB: Institut Royal des Sciences Naturelles de Belgique, Bruselas; MPG: Museo Paleontológico de Galve, Galve; MPT: Museo de Teruel, Teruel; MPZ: Museo Paleontológico de la Universidad de Zaragoza-Gobierno de Aragón, Zaragoza; NHMUK: Natural History Museum, Londres; OMNH: Oklahoma Museum of Natural History, Norman; UAM: colecciones de la Unidad de Paleontología de la Universidad Autónoma de Madrid, Cantoblanco.
}

\section{Situación geográfica y geológica}

La localidad de Galve se ubica en el centro la provincia de Teruel (comunidad autónoma de Aragón, España) y forma parte de la comarca del mismo nombre (Fig. 1). Geológicamente se sitúa en la Subcuenca de Galve, una de las siete subcuencas en que se divide la Cuenca cretácica inferior del Maestrazgo (véanse referencias en Ruiz-Omeñaca et al., 2004a). 


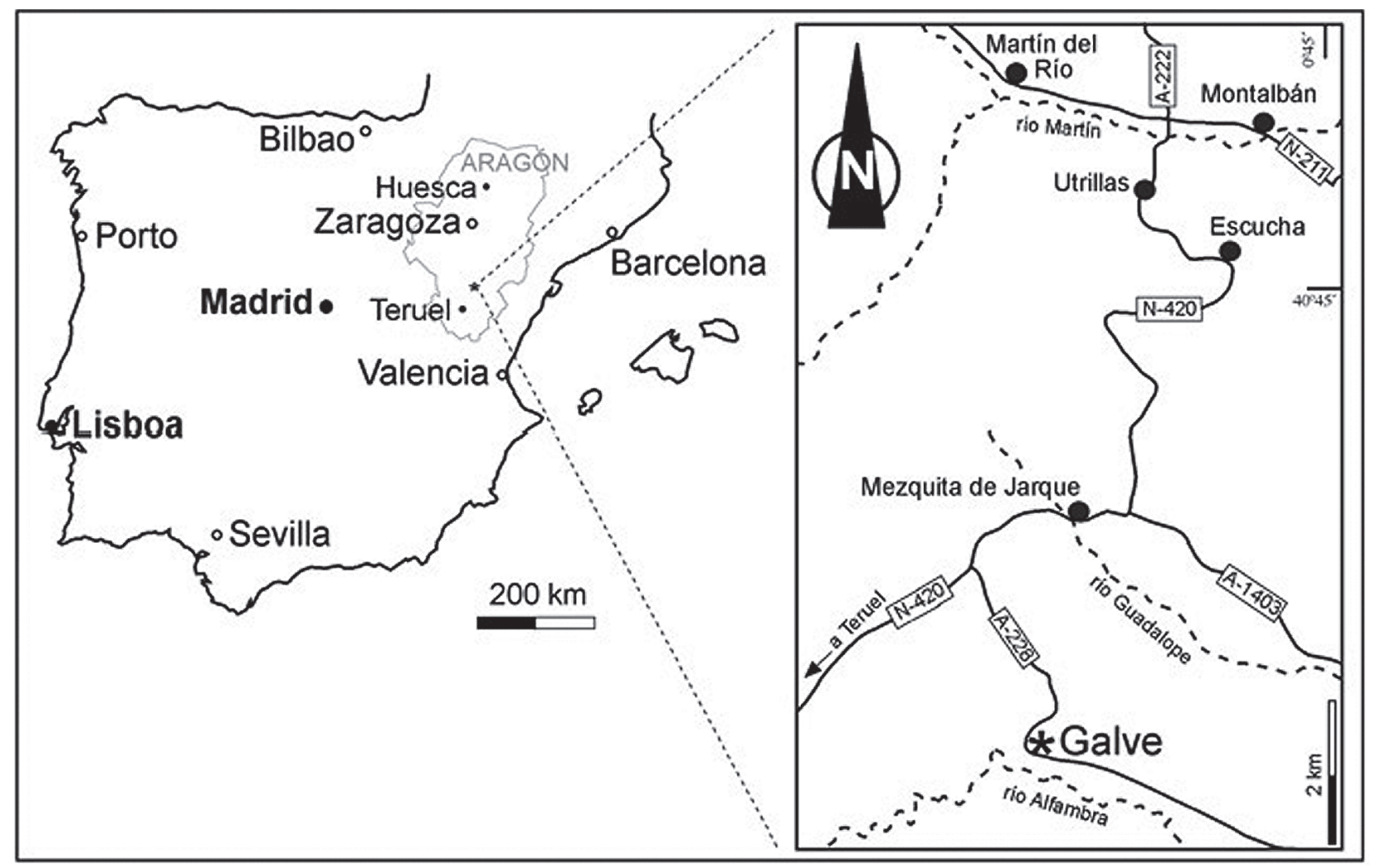

Fig. 1.-Situación geográfica de Galve. Tomado de Ruiz-Omeñaca et al. (2004a: fig. 1).

El área de Galve es bien conocida internacionalmente por los investigadores de vertebrados mesozoicos, debido a la abundancia y diversidad de restos con los que se han descrito nuevos taxones de tiburones, anfibios, dinosaurios y mamíferos (véase Ruiz-Omeñaca et al., 2004a).

En la colina denominada La Maca, situada a unos 2 $\mathrm{Km}$ al W de Galve (Ruiz-Omeñaca et al., 2004a: fig. 3), se han descubierto restos fósiles en cuatro yacimientos localizados en la parte media de la Formación Camarillas (Barremiense inferior; Ruiz-Omeñaca et al., 2004a: fig. 2), numerados de base a techo como:

- La Maca 1, yacimiento del que procede una vértebra caudal de iguanodontoideo figurada por Sanz et al. (1990: fig. 25) como Iguanodon (MPG$\mathrm{MH}$; Iguanodontoidea indet. en Ruiz-Omeñaca, 2006: 170) y una escápula de ornitópodo de gran tamaño que no ha sido descrita ni figurada, y que podría pertenecer al mismo iguanodontoideo que la vértebra caudal.

- La Maca 2, yacimiento con bivalvos; es el yacimiento-tipo del uniónido Elliptio galvensis Mongin 1966 (Mongin, 1966; fósiles en paradero desconocido).
- La Maca 3, citado en trabajos anteriores como «Corral de la Maca» (Fernández-Galiano, 1958) o simplemente «La Maca» (Fernández-Galiano, 1960; Lapparent, 1960, Buscalioni \& Sanz, 1984), es el yacimiento del que proceden los restos del nuevo iguanodontoideo descrito en este trabajo; de este yacimiento proceden también tres dientes de terópodo (MPZ98/2, MPZ2005/316, MPZ2005/317, Allosauridae? indet.; Ruiz-Omeñaca et al., 2005); Lapparent (1960) también cita en este yacimiento restos de peces, tortugas y cocodrilos, cuyo paradero actual es desconocido.

- La Maca 4, con osteodermos de cocodrilo sin describir (MPZ/sin sigla).

\section{Paleontología sistemática}

ORNITHISCHIA SEELEY 1888

ORNITHOPODA MARSH 1881

IGUANODONTIA DOLLO 1888 BAUR 1891 (non

SERENO 1986)

DRYOMORPHA SERENO 1986

ANKYLOPOLLEXIA SERENO 1986

IGUANODONTOIDEA BONAPARTE 1850 

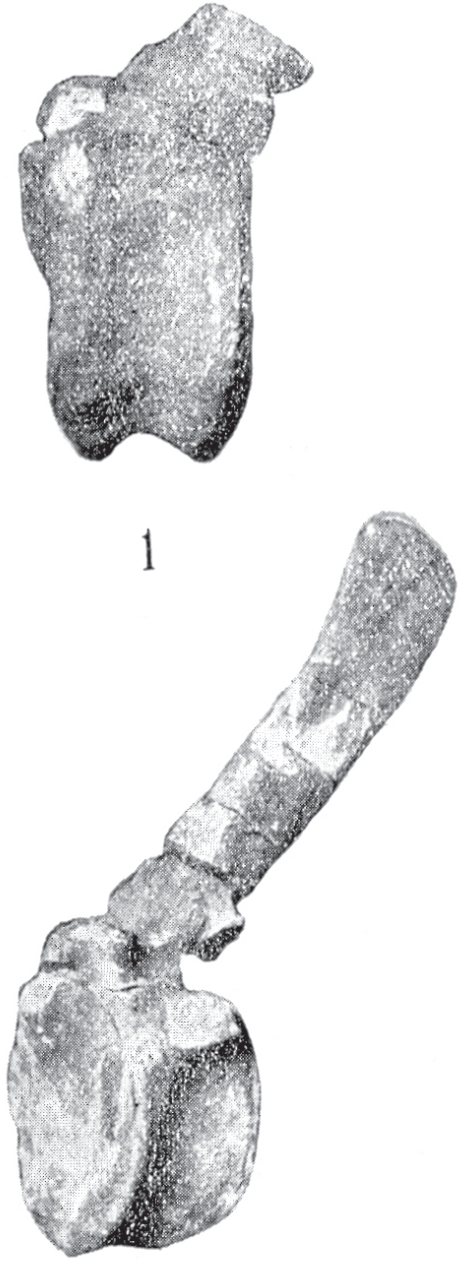

4

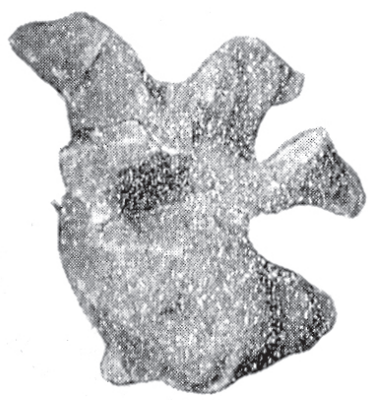

m

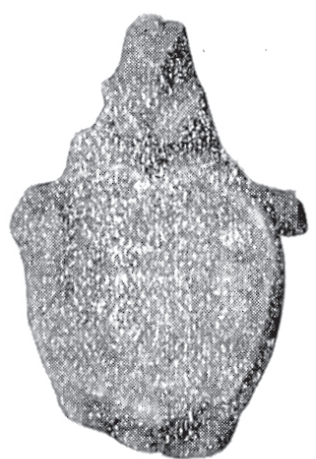

2
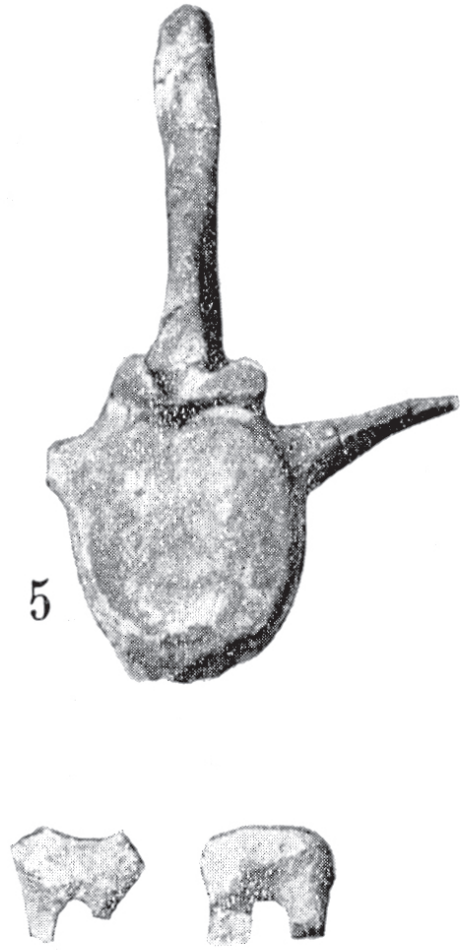

8

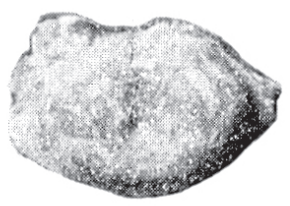

9

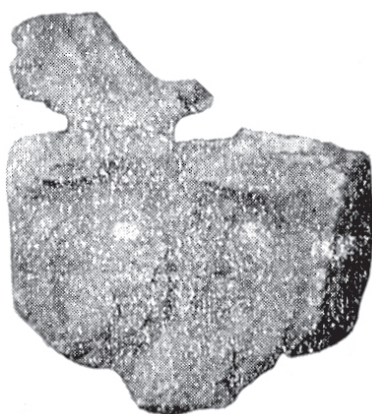

3
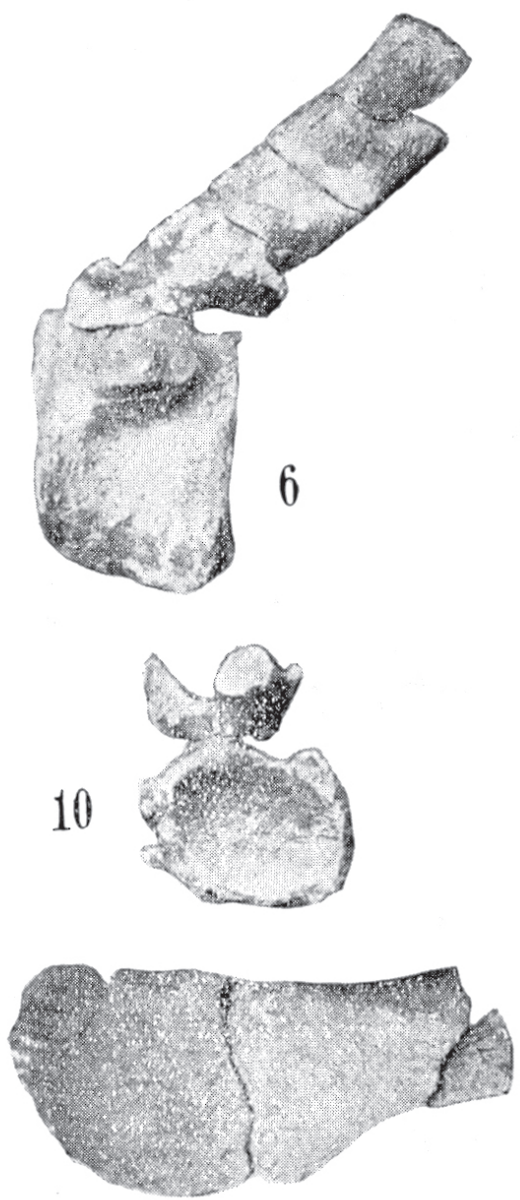

11

Fig. 2.-Figuración original de Lapparent de varios de los restos de Delapparentia turolensis nov. gen. et sp. de La Maca 3, Galve (Teruel, Barremiense inferior). Tomado de Lapparent (1960: lám. 1). Nótese que las fotografías 7 y 8 están intercambiadas en el pie de figura original: 7 es una vértebra cervical y 8 son los arcos hemales.

1: vértebra caudal MPT/I.G.451, 2: vértebra caudal MPT/I.G.454, 3: vértebras caudales fusionadas MPT/I.G.459-460, 4: vértebra caudal MPT/I.G.452, 5: vértebra caudal MPT/I.G.456, 6: vértebra caudal MPT/I.G.457, 7: vértebra cervical MPT/I.G.447, 8: dos chevrones MPT/I.G.466, MPT/I.G.467, 9: vértebra cervical MPT/I.G.446, 10: vértebra cervical MPT/I.G.448, 11: pubis izquierdo MPT/I.G.471, en vistas lateral izquierda $(1,4,6,11)$, lateral derecha $(3)$, anterior $(5,7,9)$, posterior $(2,10)$ y anterior/posterior $(8)$. 


\section{Delapparentia nov. gen.}

Etimología: dedicado a Albert Félix de Lapparent (19051975), que estudió el esqueleto de La Maca 3 y fue pionero en el estudio de los dinosaurios españoles, publicando en 1960 la primera monografía sobre el tema en España, concretamente el trabajo «Los dos dinosaurios de Galve» en la revista Teruel (Lapparent, 1960) (véase Bordet, 1977 y Alcalá, 2005).

Especie tipo: Delapparentia turolensis nov. sp., por monotipia.

Diagnosis: la misma que la de la especie tipo y única especie conocida.

Distribución: Barremiense inferior (Cretácico Inferior).

\section{Delapparentia turolensis nov. sp. (Figs. 2-8, Apéndice 1)}

Denominaciones anteriores de este taxón (sólo se citan los trabajos en los que se describe o figura material):

$\begin{array}{lll}1960 & \begin{array}{l}\text { Iguanodon bernissartensis } \\ \text { BoulENGER }\end{array} & \begin{array}{l}\text { Lapparent, p. 183, } \\ \text { fig. 5, lám. 1 }\end{array} \\ 1984 & \begin{array}{l}\text { I. bernissartensis } \\ \text { «Iguanodontidae» indet. }\end{array} & \begin{array}{l}\text { Buscalioni \& Sanz, p. 14 } \\ \text { Ruiz-Omeñaca \& Canudo, } \\ \text { p. 275, fig. 4G }\end{array} \\ 2003 & \begin{array}{l}\text { «Iguanodóntido» } \\ \text { de La Maca }\end{array} & \begin{array}{l}\text { Ruiz-Omeñaca } \text { et al., } \\ \text { p. 149 }\end{array} \\ 2004 b & \begin{array}{l}\text { La Maca «iguanodontid» } \\ \text { Ruiz-Omeñaca } \text { et al., p. } 41\end{array} \\ 2006 & \begin{array}{l}\text { Delapparentia turolensis } \\ \text { nov. sp. (nomen nudum) } \\ \text { nueva especie } \\ \text { de iguanodóntido }\end{array} & \begin{array}{l}\text { figs. } 4.2 .24-4.2 .36 \\ \text { Royo-Torres \& Cobos, } \\ \text { p. 70, fig. 7 }\end{array} \\ & \end{array}$

Etimología: Dedicado a la provincia de Teruel, una de las más ricas en restos de dinosaurios en España, de la que procede el holotipo. También el nombre específico es un reconocimiento a la revista Teruel, en la que se publicaron las primeras descripciones de los restos de Delapparentia turolensis (Lapparent, 1960; Buscalioni \& Sanz, 1984).

Localidad tipo: La Maca 3, Galve, Teruel, España. Formación Camarillas.

Distribución: Barremiense inferior (Cretácico Inferior).

Holotipo: esqueleto postcraneal parcial y semi-articulado $(\mathrm{MPT} / \mathrm{I} . \mathrm{G} .=$ = Museo Provincial de Teruel, Iguanodon, Galve»), descrito y figurado como Iguanodon bernissartensis por Lapparent (1960: fig. 5, lám. 1) (Fig. 2), formado por cuatro vértebras cervicales, un centro y varios fragmentos de arcos neurales de vértebras dorsales, tres centros y varios fragmentos de espinas neurales de vértebras sacras, nueve vértebras caudales anteriores, fragmentos de costillas cervicales y dorsales, cinco chevrones, numerosos fragmentos de tendones osificados, y la cadera izquierda incompleta (ilion, prepubis y fragmento proximal de isquion).

Depósito: Museo de Teruel (MPT); parte del material se expone en la sede de Dinópolis en Galve [FCPT-D].

Diagnosis: dinosaurio euornitópodo iguanodontoideo caracterizado por las siguientes autapomorfías: costillas esternales osificadas, costillas dorsales posteriores con capítulo y tubérculo no fusionados, e ilion con el proceso preacetabular horizontal, torsionado y expandido lateromedialmente (compartido con Zalmoxes WeISHAMPEL, Jianu, CSIKI et Norman 2003, Weishampel et al., 2003; Godefroit et al., 2009). Además presenta costillas dorsales anteriores con un foramen neumático, e isquion grande en relación al ilion.

\section{Descripción}

El material tipo de Delapparentia turolensis está compuesto por restos postcraneales de un único individuo. La mayoría de las vértebras caudales forman una serie continua, por lo que probablemente el ejemplar era un esqueleto en conexión anatómica.

Lapparent (1960: 195, fig. 5, lám. 1) cataloga los restos existentes como: 4 vértebras cervicales $\left(\mathrm{V}^{1-4}\right)$ (Figs. 2.7, 2.9, 2.10), 2 vértebras sacras $\left(\mathrm{V}^{5}\right), 14$ vértebras caudales $\left(\mathrm{V}^{5 \text { bis-18}}\right)$ (Figs. 2.1-2.6), 28 neurapófisis $\left(\mathrm{V}^{41-55}\right), 5$ arcos hemales ( $\left.\mathrm{V}^{19-22 \mathrm{bis}}\right)$ (Fig. 2.8), numerosos tendones osificados (To), 14 costillas (Co), 1 ilion (Il) y 1 pubis (Pu) (Fig. 2.11). El listado completo se recoge en el Apéndice 1.

Además, pertenecen a Delapparentia turolensis dos fragmentos de arco neural (UAM/sin sigla), asignados por Buscalioni \& Sanz (1984) a I. bernissartensis, y algunos restos catalogados por Lapparent (1960) como pertenecientes al saurópodo de Las Zabacheras [=Aragosaurus ischiaticus SANZ, BUSCALIONI, CASAnOvas et SANTAFÉ 1987]

Los yacimientos de La Maca 3 y Las Zabacheras se descubrieron y excavaron a la vez (Fernández-Galiano, 1958, 1960), y los materiales fueron llevados al Museo de Teruel, donde se mezclaron y donde Lapparent los separó según su morfología (véase Alcalá, 2005). Los restos que se identificaron como del saurópodo de Las Zabacheras y proceden en realidad de La Maca 3 son:

- MPT/I.G.478 $\left(\mathrm{V}^{6 \mathrm{~s}}\right)$ : fragmento de sacro, inventariado por Lapparent (1960: 195) como vértebra caudal de saurópodo,

- MPT/I.G.481 partim $\left(\mathrm{Co}^{\mathrm{s}}\right)$ : costilla dorsal, identificada y figurada por (Lapparent, 1960: 189, lám. 2, fig. 6) como costilla cervical de saurópodo,

- MPT/I.G.481 partim $\left(\mathrm{Co}^{\mathrm{s}}\right)$ : costilla dorsal posterior, inventariada por Lapparent (1960: 195) como costilla de saurópodo,

- MPT/I.G.488 (Is $\left.{ }^{\mathrm{s}}\right)$ : isquion izquierdo, descrito como isquion de saurópodo (Lapparent, 1960: 190),

- MPT/I.G.sin sigla $\left(\mathrm{X}^{\mathrm{s}}\right)$ : fragmento de prepubis, identificado por Lapparent (1960: 195) como hueso indeterminado de saurópodo

\section{Esqueleto axial}

Hay cuatro vértebras cervicales, MPT/I.G.446 ( $\left.{ }^{1}\right)$, MPT/I.G.447 (V2), MPT/I.G.448 (V $\left.{ }^{3}\right)$ у MPT/I.G.449 (V $\left.{ }^{4}\right)$, todas incompletas, que conservan los centros y parte de los arcos neurales. Son cortas, y opistocélicas (Figs. 2.7, 2.9, 2.10). Las prezigapófisis están unidas a la parapófisis, y las postzigapófisis están situadas en el extremo de unos procesos postzigapofisiarios alargados (Fig. 2.7).

Buscalioni \& Sanz (1984: 15) describen una postzigapófisis izquierda de una vértebra cervical y un proceso transverso de vértebra dorsal (UAM/sin sigla) que por su tamaño y morfología pueden pertenecer al mismo ejemplar que el holotipo de Delapparentia turolensis.

Hay un único centro de vértebra dorsal, MPT/I.G.458 ( $\left.{ }^{13}\right)$, aunque los numerosos fragmentos de arcos neurales dorsales indican que debía haber varias vértebras dorsales en el yacimiento. Está mal conservado y presenta restos de los pedicelos del arco neural. Aparentemente es anficélico o anfiplático, y tiene las caras articulares más altas que anchas. Sobre las caras laterales hay restos de lo que podrían ser las parapófisis, 


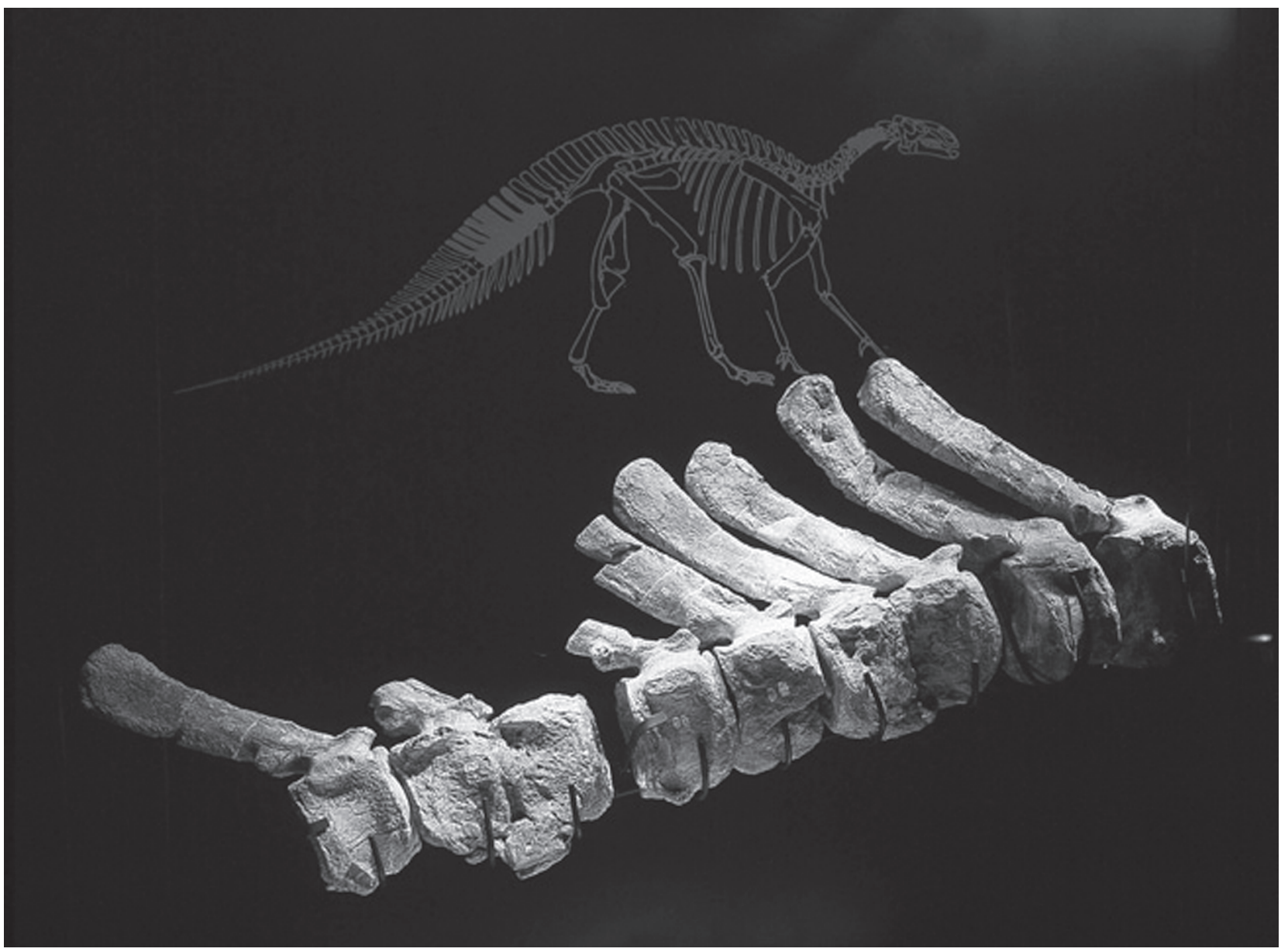

Fig. 3.-Vértebras caudales de Delapparentia turolensis nov. gen. et sp. de La Maca 3 Galve (Teruel, Barremiense inferior) en exhibición en Dinópolis-Teruel en 2002, en vista lateral derecha. Tomado de Royo-Torres y Cobos, (2007: fig. 7).

De derecha a izquierda son: MPT/I.G.451, MPT/I.G.452, MPT/I.G.456-455, MPT/I.G.457, MPT/I.G.454, MPT/I.G.459-460 y MPT/I.G.461; nótese que este no es el orden real de la serie caudal (véase texto). Obsérvese que hay dos parejas de vértebras fusionadas entre sí, la $3^{\mathrm{a}}$ y $4^{\mathrm{a}}$ (MPT/I.G.456-455) y la $7^{\mathrm{a}}$ y la $8^{\mathrm{a}}$ (MPT/I.G.459-460) empezando por la derecha.

que están erosionadas, lo que indicaría una posición anterior en la serie dorsal. La superficie ventral tiene una quilla muy suave.

Del sacro se conserva un fragmento, MPT/I.G.450 ( $\left.{ }^{5}\right)$, formado por el último centro sacro y parte del penúltimo centro. La únicas observaciones posibles en él son que la cara articular posterior es plana (ya mencionado por Lapparent, 1960: 184), y que la superficie ventral es quillada y no presenta surco. También pueden pertenecer al sacro de Delapparentia la pieza MPT/I.G.478, inventariada por Lapparent (1960) como vértebra caudal del saurópodo de Las Zabacheras [=Aragosaurus ischiaticus] $\left(\mathrm{V}^{6 \mathrm{~s}}\right)$. Dicha pieza conserva dos vértebras fusionadas entre si, cilíndricas, que se estrechan ligeramente en la zona de fusión. La superficie ventral es ligeramente quillada. Por su forma estrecha podrían ser de la mitad del sacro.

Lapparent (1960: 195) lista catorce vértebras caudales $\left(V^{5 b i s}\right.$ a $\mathrm{V}^{18}$, aunque cuatro de ellas no lo son:

- MPT/I.G.453 $\left(\mathrm{V}^{8}\right)$ es un fragmento de centro vertebral de gran diámetro, que se ha identificado como un fragmento de vértebra caudal de Aragosaurus ischiaticus, comparando con las vértebras completas de dicho taxón descritas por Sanz et al. (1987), así como a la figurada por Lapparent (1960: fig. 7).

- MPT/I.G.458 $\left(\mathrm{V}^{13}\right)$ es, como se ha descrito más arriba, un centro de vértebra dorsal.

- MPT/I.G.462 $\left(\mathrm{V}^{17}\right)$ es un centro vertebral muy mal conservado, de $120 \mathrm{~mm}$ de longitud, con una superficie articular cóncava de 120 x $110 \mathrm{~mm}$. Podría tratarse de una vértebra cervical.

- MPT/I.G.463 $\left(\mathrm{V}^{18}\right)$ es medio centro vertebral muy mal conservado (longitud $110 \mathrm{~mm}$, altura superficies articulares 110 y $125 \mathrm{~mm}$ ), que no puede identificarse como dorsal o caudal y que incluso podría ser de Aragosaurus ischiaticus.

Además, la vértebra $\mathrm{V}^{5 \text { bis }}$ no ha podido localizarse entre el material del Museo de Teruel.

MPT/I.G.451 $\left(\mathrm{V}^{6}\right)$, MPT/I.G.452 $\left(\mathrm{V}^{7}\right)$, MPT/I.G.454-457 $\left(\mathrm{V}^{9}-\mathrm{V}^{12}\right)$ y MPT/I.G.459-461 $\left(\mathrm{V}^{14}-\mathrm{V}^{16}\right)$ son nueve vértebras caudales anteriores, que conservan los centros y poseen procesos transversos sobre el centro, y largas espinas neurales con las postzigapófisis unidas a su base (Figs. 2.1-2.6, Fig. 3). Estas nueve vértebras forman una serie discontinua. MPT/I.G.451 $\left(=\mathrm{V}^{6}\right)$ puede reconocerse como la primera vértebra caudal por- 
que carece de facetas para los chevrones. MPT/I.G.452 $\left(=\mathrm{V}^{7}\right)$ podría ser la segunda o tercera vértebra caudal y sólo presenta faceta posterior para el chevrón; posiblemente sea la tercera caudal puesto que no encaja con la primera vértebra caudal.

MPT/I.G.457 $\left(=\mathrm{V}^{12}\right)$, MPT/I.G.454 $\left(=\mathrm{V}^{9}\right)$ y MPT/I.G.456$455\left(=\mathrm{V}^{11}-\mathrm{V}^{10}\right)$ forman una serie continua, pudiendo faltar una vértebra entre MPT/I.G.452 $\left(=\mathrm{V}^{7}\right)$ y MPT/I.G.457 $\left(=\mathrm{V}^{12}\right)$. Por detrás de MPT/I.G.455 $\left(=\mathrm{V}^{10}\right)$ se situarían MPT/I.G.459-460 $\left(=\mathrm{V}^{14}-\mathrm{V}^{15}\right)$, pudiendo faltar una vértebra en medio y la última de la serie sería MPT/I.G.461 $\left(=\mathrm{V}^{16}\right)$, pudiendo de nuevo faltar una vértebra entre MPT/I.G.460 $\left(=\mathrm{V}^{15}\right)$ y MPT/I.G.461 $\left(=\mathrm{V}^{16}\right)$. MPT/I.G.459-460 $\left(=\mathrm{V}^{14}-\mathrm{V}^{15}\right)$ están cizalladas por deformación tectónica por lo que es muy probable que se encontraran desarticuladas y en distinta posición que el resto (por ejemplo todas en posición horizontal y éstas en posición vertical) y se han comportado de diferente modo ante la presión litostática y/o tectónica.

La serie caudal está formada de esta manera: $\mathrm{V}^{6}-$ ? - $\mathrm{V}^{7}-$ ? $\mathrm{V}^{12}-\mathrm{V}^{9}-\mathrm{V}^{11}-\mathrm{V}^{10}-$ ?- $\mathrm{V}^{14}-\mathrm{V}^{15}-$ ? - $\mathrm{V}^{16}$. Todas las vértebras presentan procesos transversos; en Ouranosaurus TAQUET 1976 y Dollodon los procesos transversos desaparecen en la caudal 15 (Taquet, 1976: 118; Norman, 1986: 310 como I. atherfieldensis). Si el orden propuesto es correcto, en Delapparentia habría procesos transversos hasta al menos la caudal 13, y el primer chevrón aparecería entre las caudales 3 y 4 , al igual que en Iguanodon bernissartensis y Ouranosaurus (Taquet, 1976: 119); en Dollodon aparecen entre las caudales 2 y 3 (Norman, 1986: 310, como I. atherfieldensis).

Las vértebras caudales tienen los centros anficélicos, con caras articulares más altas que anchas, espinas neurales largas e inclinadas posteriormente y con las postzigapófisis dispuestas sobre la espina neural. Los procesos transversos están rotos en la mayoría de las vértebras, pero puede observarse que sus bases son anchas y dispuestas horizontalmente y centradas en el borde dorsal del centro. El proceso transverso izquierdo de MPT/I.G.456 $\left(=\mathrm{V}^{11}\right)$ está completo y es relativamente largo y afilado en vista anterior (Lapparent, 1960: lám. 1, fig. 5) (Fig. 2.5). Las facetas para el chevrón (hemapófisis) están muy desarrolladas, estando la faceta posterior más inclinada que la faceta anterior.

Hay dos pares de vértebras caudales fusionadas entre sí: MPT/I.G.456-455 $\left(=\mathrm{V}^{11}-\mathrm{V}^{10}\right)$ y MPT/I.G.459-460 $\left(=\mathrm{V}^{14}-\mathrm{V}^{15}\right)$ (véase la Fig. 3). Lapparent (1960: 184, lám. 1, fig. 3) ya destaca que «la pieza numerada $\mathrm{V}^{14-15}$ representa dos vértebras coosificadas» (Fig. 2.3), diciendo que «este fenómeno de osificación ha sido señalado en varias ocasiones para las vértebras de los dinosaurios». Sin embargo, Lapparent no menciona la existencia de la pareja MPT/I.G.456-455 $\left(=\mathrm{V}^{11}-\mathrm{V}^{10}\right)$, y figura MPT/I.G.456 aislada (Lapparent, 1960: lám. 1, fig. 5) (Fig. 2.5). La fusión se desarrolla mediante ligamentos osificados cruzados («spanning ossified ligaments», Rothschild \& Berman, 1991) que se disponen irregularmente entre los centros.

La fusión sólo se produce entre los centros no entre los arcos neurales, estando las prezigapófisis, postzigapófisis y espinas neurales libres de osificación suplementaria. En el par MPT/I.G.459-460 $\left(=\mathrm{V}^{14}-\mathrm{V}^{15}\right)$ la fusión afecta al chevrón situado por debajo de ambas caudales (Figs. 2.3 y 3), hecho mencionado por Lapparent (1960: 184): «la primera de las dos [ [ $\left.{ }^{14}\right]$ muestra el arranque del arco hemal en dos láminas bastante delgadas».

Este tipo de fusión vertebral que no afecta al arco neural se ha identificado como DISH («diffuse idiopathic skeletal hype- rostosis», hiperostosis esqueletal idiopática difusa en castellano) y no es una patología sino una respuesta fisiológica al estrés, que permite mantener alta la cola (véase Rothschild \& Berman, 1991; Rothschild, 1997; Tanke \& Rothschild, 1997, 2002). Aunque la DISH en dinosaurios ha sido descrita principalmente en saurópodos (Rothschild \& Berman, 1991), también hay posibles ejemplos en terópodos (Allosaurus MARsh 1877, Tanke \& Rothschild, 2002: 84, 88; Tyrannosaurus OsBORN 1905, Tanke \& Rothschild, 2002: 50), y se ha citado en ornitópodos (Camptosaurus MARSH 1885 y hadrosáuridos, Tanke \& Rothschild, 2002: 76, 84), ceratopsios (Pachyrhinosaurus STERNBERG 1950, Tanke \& Rothschild, 2002: 50, 84) y paquicefalosaurios (Tanke \& Rothschild, 2002: 76, 84).

Norman (1980: 44) menciona que, en Iguanodon bernissartensis, «no es infrecuente encontrar dos vértebras caudales fusionadas juntas; es indudablemente una condición patológica resultante de una lesión durante la vida del dinosaurio».

Rothschild \& Berman (1991) proponen, para los saurópodos, que la presencia de DISH en el $50 \%$ de los ejemplares de Diplodocus MARSH 1878 y Apatosaurus MARSH 1877 y en el 25\% de los de Camarasaurus CoPe 1877 examinados, podría indicar dimorfismo sexual, apareciendo el DISH en las hembras; el refuerzo de la cola en las hembras permitiría mantener la cloaca en una posición más accesible para la cópula (véase también Tanke \& Rothschild, 1997, 2002).

Entre el material del Museo de Teruel hay varias espinas neurales caudales que carecen de centro vertebral (MPT/I.G.468, véase Apéndice 1), lo que indica que había en el yacimiento bastantes más vértebras caudales que las recuperadas.

Hay restos de costillas y chevrones. Lapparent (1960: 185) señala seis fragmentos de chevrones (arcos hemales) y catorce fragmentos de costillas torácicas. Entre las costillas se han identificado costillas cervicales y costillas dorsales.

Las costillas cervicales (Fig. 4A-C) tienen el capítulo terminado en forma de maza, como en Iguanodon y Dollodon (Norman, 1980: fig. 33, 1986: fig. 28 como I. atherfieldensis), y el tubérculo de sección aplastada lateromedialmente. Hay pequeños fragmentos rotos que podrían ser diáfisis de costillas cervicales, pero no ha podido reconstruirse ninguna.

Entre las costillas dorsales se han identificado costillas dorsales anteriores y costillas dorsales posteriores. Las costillas dorsales anteriores (Fig. 4D-G) son similares a las de Iguanodon y Mantellisaurus (Norman, 1980: figs. 41, 42, 1986: fig. 33 como I. atherfieldensis), con un proceso capitular muy desarrollado al final del cual se dispone el capítulo, y un tubérculo reducido a un pequeño proceso en la zona de curvatura de la diáfisis.

Una de las costillas identificadas por Lapparent como costilla cervical de saurópodo [Aragosaurus ischiaticus] (Lapparent, 1960: 189, lám 2, fig. 6), MPT/I.G.481 partim (=Co ${ }^{\mathrm{s}}$ ), pertenece realmente a Delapparentia (como pone de manifiesto la matriz adherida a ella, diferente de la del yacimiento de Las Zabacheras y similar al de La Maca 3), y se ha identificado como costilla dorsal anterior (Fig. 4F). Esta costilla es característica por tener un foramen neumático debajo del tubérculo (Fig. 4G), lo que podría constituir una autapomorfía de Delapparentia turolensis, aunque no se ha incluido como tal en la diagnosis pues se desconoce si otros iguanodontoideos podrían presentar este carácter.

Con los fragmentos no siglados del Museo de Teruel se han podido reconstruir dos costillas dorsales posteriores (Fig. 4H-I; 


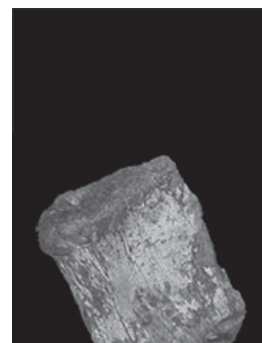

A
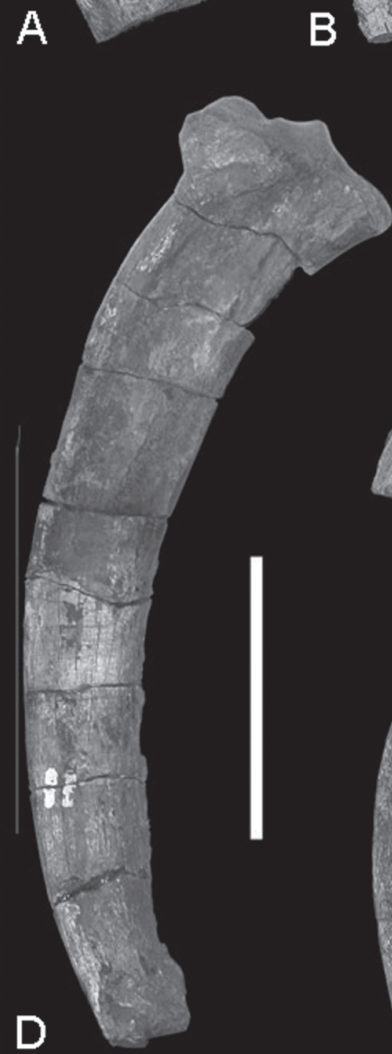

B
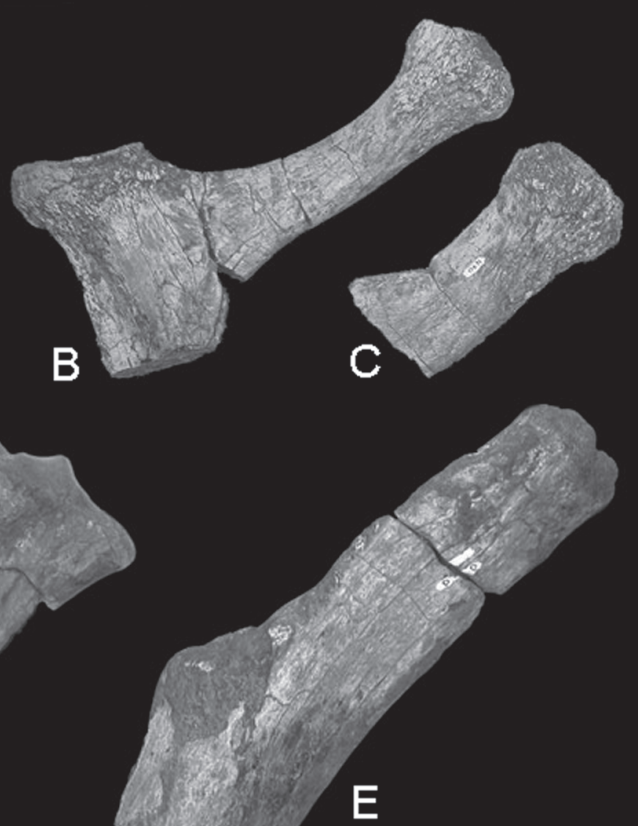

E

D

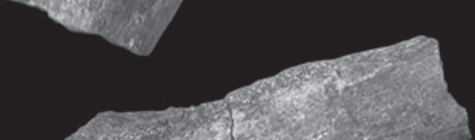

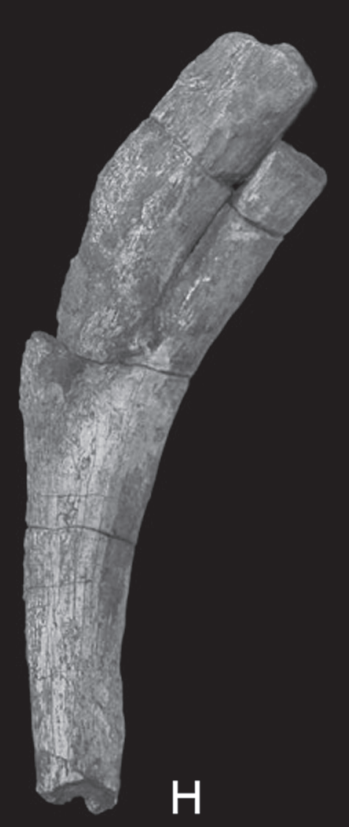

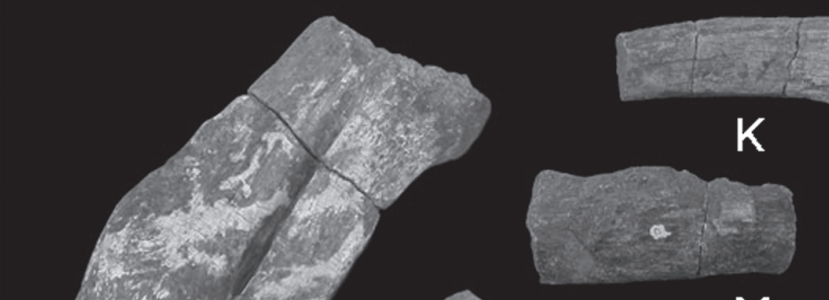

M

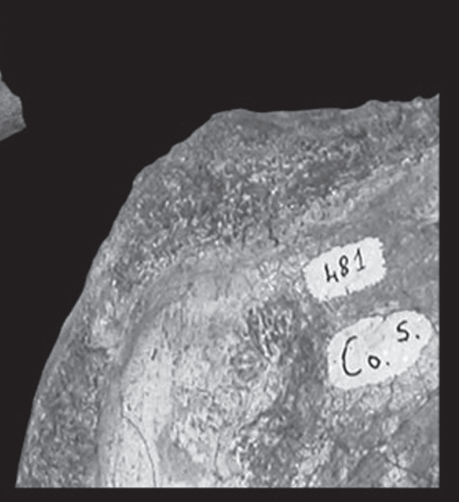

G

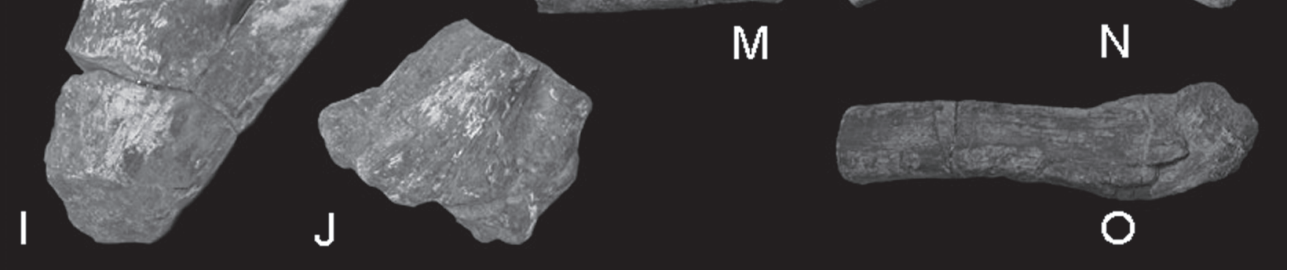

Fig. 4.-Costillas de Delapparentia turolensis nov. gen. et sp. de La Maca 3, Galve (Teruel, Barremiense inferior). Escala: $10 \mathrm{~cm}$. AC: MPT/I.G.470 partim: costillas cervicales, en vista posterior. A: tubérculo aislado; B: extremo proximal completo; C: extremo proximal de capítulo. D-G: costillas dorsales anteriores, en vista posterior. D: MPT/I.G.sin sigla, diáfisis de costilla. E: MPT/I.G.470 partim, extremo proximal completo. F-G: MPT/I.G.481 partim: fragmento proximal; G: detalle del foramen neumático. H-J: costillas dorsales posteriores, en vista posterior. H: MPT/I.G.481( $\left.\mathrm{Co}^{\text {s}}\right)$ partim; I: MPT/I.G.sin sigla; J: MPT/I.G.sin sigla. K-O: MPT/I.G.sin sigla: fragmentos de costillas esternales. 


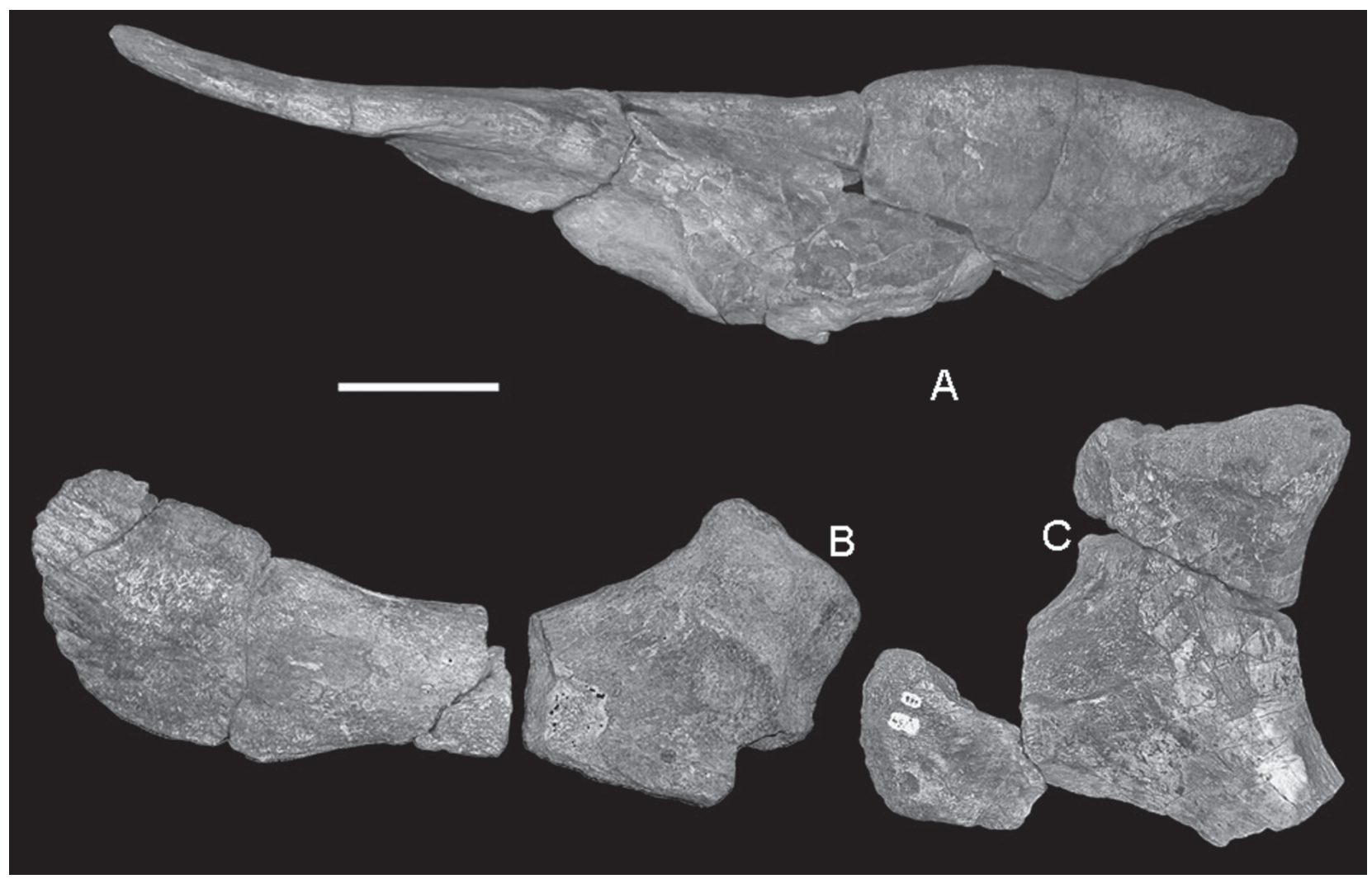

Fig. 5.-Cadera izquierda de Delapparentia turolensis nov. gen. et sp. de La Maca 3, Galve (Teruel, Barremiense inferior) en vista lateral. Escala: $10 \mathrm{~cm}$. A: MPT/I.G.472: ilion; B: MPT/I.G.471 +MPT/I.G.sin sigla(Xs): pubis; C: MPT/I.G.488 +MPT/I.G.468(V4): isquion. Las letras A-B-C delimitan el posible desarrollo del acetábulo.

parte de una de ellas siglada como MPT/I.G.481 partim $\left(=\mathrm{Co}^{\mathrm{s}}\right)$, identificada como saurópodo [=Aragosaurus ischiaticus] por Lapparent), y hay además un fragmento de una posible tercera costilla dorsal distal, con la zona donde capítulo y tubérculo comenzarían a desarrollarse (Fig. 4J). Las costillas identificadas como dorsales posteriores son características por presentar capítulo y tubérculo alargados, paralelos, con una hendidura intermedia, y fusionados proximalmente (Fig. 4H-I).

Esta peculiar forma de las costillas dorsales posteriores podría ser una autapomorfía de Delapparentia turolensis. En Iguanodon bernissartensis y Mantellisaurus atherfieldensis todas las costillas dorsales excepto la última tienen dos cabezas articulares (Norman, 1980: 40, 1986: 305), en Ouranosaurus las tres últimas costillas dorsales posteriores tienen capítulo y tubérculo fusionados (Taquet, 1976: 121).

Entre los fragmentos sin sigla del Museo de Teruel se han podido reconstruir varios fragmentos alargados, de sección elíptica y forma algo irregular que se han identificado como costillas esternales osificadas (Fig. 4K-O). Este carácter es una sinapomorfía de Hypsilophodontidae según Sereno (1986) y ha sido citado también en el iguanodontio Macrogryphosaurus CAlvo, Porfiri et Novas 2007 (Calvo et al., 2007) (véase Comparación y discusión). La presencia de costillas esternales osificadas en las costillas dorsales anteriores podría ser una autapomorfía de Delapparentia turolensis, y una convergencia con los hypsilofodóntidos y Macrogryphosaurus.
Los chevrones tienen el extremo proximal con las dos ramas proximales (pedicelos) fusionadas, lo que origina un canal hemal cerrado (Lapparent (1960: lám. 1, fig. 8) (Fig. 2.8), y presentan una cresta transversal que separa las facetas anterior y posterior que articulan con las hemapófisis de las vértebras caudales. En Iguanodon bernissartensis los chevrones tienen las dos ramas proximales fusionadas (Norman, 1980: fig. 50), aunque los más distales tienen los pedicelos separados (Norman, 1980: fig. 48). En los hadrosáuridos los chevrones tienen «dos ramas articulares separadas, terminadas cada una de ellas en una faceta articular independiente, de modo que el canal hemal se encuentra abierto proximalmente» (Company Rodríguez, 2004: 270).

Hay numerosos fragmentos de tendones osificados, descritos por Lapparent (1960: 185) como «varillas estrechas y bastante delgadas (...) que se trata sin duda de tendones osificados como había sugerido D. Dimas Fernández-Galiano». La superficie externa de los tendones osificados es estriada, y su sección es circular o elíptica, posiblemente según la zona del tendón de la que proceda el fragmento; tendrían sección circular en el centro y elípitica en los extremos donde se adherirían a las espinas neurales de las vértebras caudales.

\section{Esqueleto apendicular}

Se han conservado fragmentos de los tres huesos de la cadera izquierda, aunque ninguno de ellos está completo (Fig. 5). No 

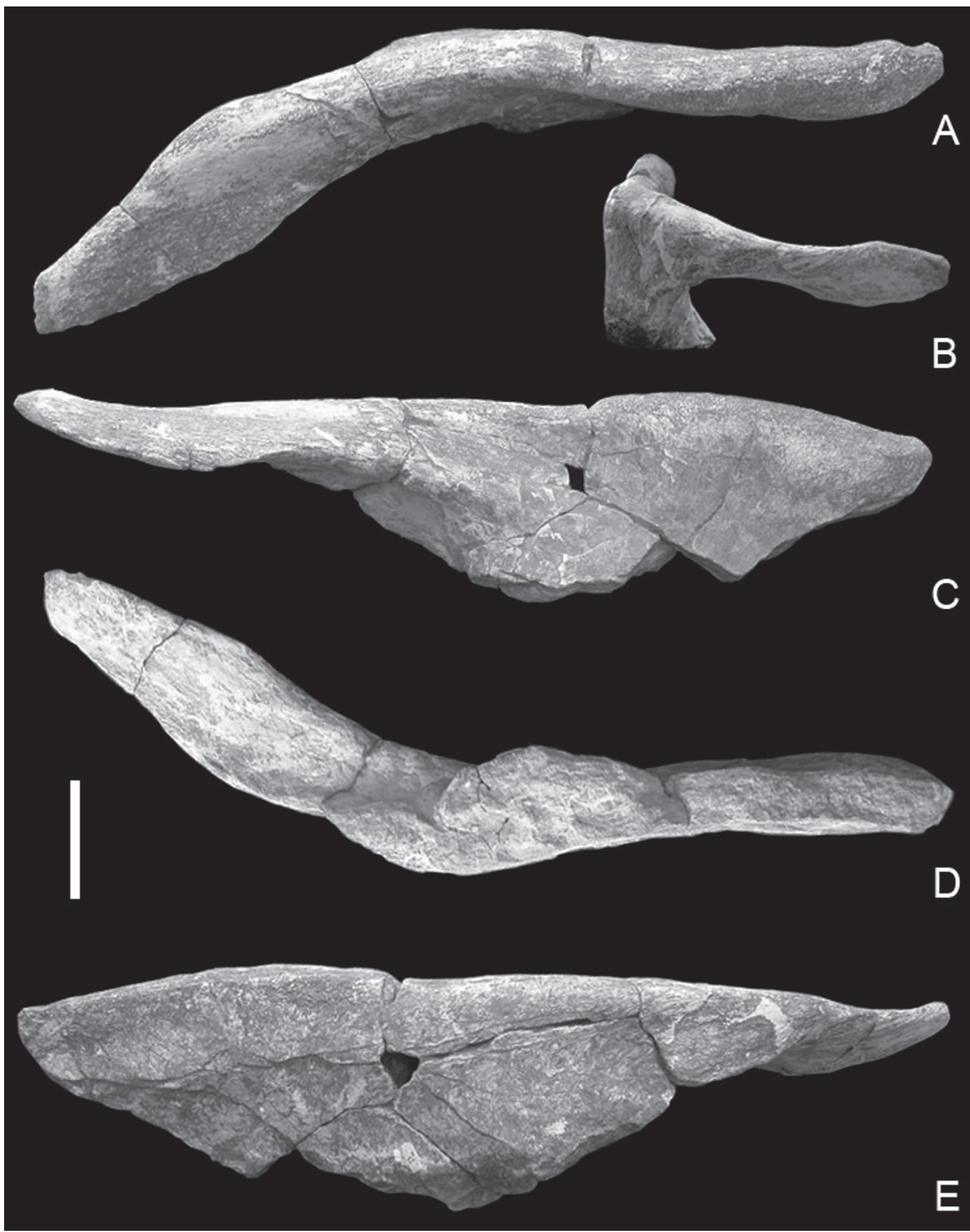

Fig. 6.-Delapparentia turolensis nov. gen. et sp. de La Maca 3, Galve (Teruel, Barremiense inferior). MPT/I.G.472: ilion izquierdo, en vistas dorsal $(A)$, anterior $(B)$, lateral $(C)$, ventral $(D)$ y medial $(E)$. Escala: $10 \mathrm{~cm}$. 

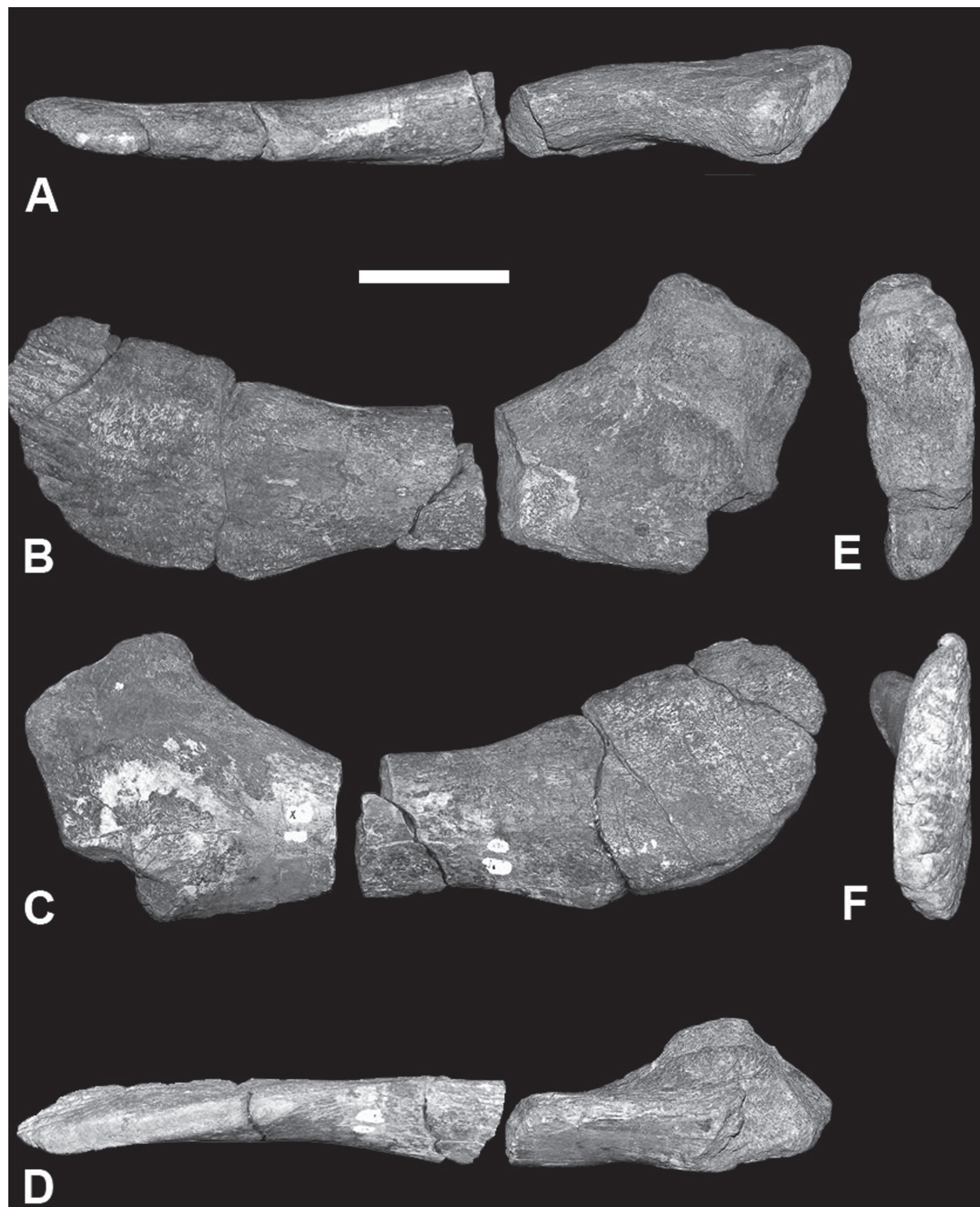

Fig. 7.-Delapparentia turolensis nov. gen. et sp. de La Maca 3, Galve (Teruel, Barremiense inferior). MPT/I.G.471 + MPT/I.G.sin sigla $\left(X^{s}\right)$ : prepubis izquierdo, en vistas dorsal $(A)$, lateral $(B)$, medial $(C)$, ventral $(D)$, posterior $(E)$ y anterior $(F)$. Escala: $10 \mathrm{~cm}$. 
obstante presentan suficientes caracteres diagnósticos que permiten comparar con otros ornitópodos, así como situar el esqueleto de La Maca 3 entre los iguanodontoideos no hadrosáuridos (véase más adelante el apartado de Comparación y discusión).

El ilion MPT/I.G.472, descrito y figurado por Lapparent (1960: 185, fig. 5), está siglado, por error, como pubis (Pu). De él se conserva el borde dorsal y el proceso preacetabular, faltando los pedicelos púbico e isquiático y la zona del acetábulo.

El ilion es un hueso plano (Figs. 5A, 6), comprimido en sentido lateromedial. Falta el borde posterior y el borde ventral, perdidos por rotura en el yacimiento. Conserva una longitud de $780 \mathrm{~mm}$ (medida paralelamente al borde dorsal), de los que 370 $\mathrm{mm}$ corresponden al proceso preacetabular (medido desde el extremo anterior del ilion hasta el borde anterior de la escotadura preacetabular) y $410 \mathrm{~mm}$ a la lámina iliaca (medido desde el borde anterior de la escotadura preacetabular hasta el borde posterior del ilion). La altura conservada es de $170 \mathrm{~mm}$ (medida perpendicularmente al borde dorsal).

La cara lateral del ilion es cóncava en sentido anteroposterior, excepto el borde posterior que es ligeramente cóncavo. En vista lateral (Fig. 6C), la lámina iliaca es convexa en sentido dorsoventral. La superficie medial es lisa y plana dorsoventralmente (Fig. 6E). El borde dorsal es rugoso en vista lateral y algo menos en vista media (Figs. 6C, E).

En vista dorsal (Fig. 6A) se observa que el ilion tiene un trazado posterior recto y se curva lateralmente.

El proceso preacetabular está torsionado, por lo que su cara lateral se convierte en dorsal. El proceso preacetabular no está inclinado ventralmente como en otros iguanodontoideos (Fig. 6C, E), y en cambio sobresale lateralmente (Fig. 6B); está expandido lateromedialmente (Figs. 6A, D) y es plano dorsoventralmente; su anchura máxima (en vista ventral) es de 120 $\mathrm{mm}$ y su extremo anterior mide $19 \mathrm{~mm}$ de altura por $67 \mathrm{~mm}$ de anchura.

Se conserva la base del pedicelo púbico, que en vista ventral (Fig. 6D) mide $90 \mathrm{~mm}$ de longitud por $40 \mathrm{~mm}$ de anchura.

En vista lateral (Fig. 6C) se observa que el ilion carece de antitrocánter (= proceso supracetabular, Horner et al., 2004: 456), que se desarrolla en los hadrosáuridos y en algunos iguanodontoideos no hadrosáuridos (véase Comparación y discusión).

Del pubis se conservan dos fragmentos del prepubis, que no llegan a encajar entre sí (Fig. 5B). El fragmento de prepubis descrito y figurado por Lapparent (1960: 186, lám. 1, fig. 11) (Fig. 2.11), MPT/I.G.471, está siglado, por error, como ilion (Il). El otro fragmento de prepubis (MPT/I.G.sin sigla) fue identificado por Lapparent como hueso indeterminado de saurópodo, y se encontraba entre el material no inventariado del Museo de Teruel, con una sigla dada por Lapparent: $\mathrm{X}^{\mathrm{s}}$ [Lapparent (1960: 195) indica que «algunos huesos indeterminados llevan la marca $\mathrm{X}$ » $\mathrm{y}$ «la letra $\mathrm{S}$ indica los huesos de Saurópodo»].

El prepubis es un hueso plano (Figs. 2.11, 5B, 7), expandido dorsoventralmente y comprimido lateromedialmente. Su altura máxima es $150 \mathrm{~mm}$ y su altura mínima $95 \mathrm{~mm}$, ambas en el fragmento más anterior. El fragmento anterior mide $340 \mathrm{~mm}$ y el posterior $240 \mathrm{~mm}$ (longitud máxima, no en posición anatómica), la longitud estimada de todo el prepubis es de $550 \mathrm{~mm}$.

En vista lateral (Fig. 7B) el extremo anterior del prepubis presenta diez surcos longitudinales para inserción muscular; dichos surcos tienen una longitud máxima de $75 \mathrm{~mm}$ y una pro- fundidad máxima de $7 \mathrm{~mm}$. Además de por surcos, el prepubis está ornamentado por rugosidades en la mitad ventral. El prepubis se estrecha en mitad de la diáfisis (Fig. 7B-C), como en Iguanodon bernissartensis (véase Comparación y discusión). El borde dorsal del prepubis es cóncavo y el borde ventral convexo anteriormente y cóncavo posteriormente (Figs. 5B, 7B-C).

En vista medial el prepubis es liso, sin rugosidades. En vista anterior (Fig. 7F) el prepubis mide $23 \mathrm{~mm}$ de anchura por 150 mm de altura, y se observa que la lámina prepúbica y la diáfisis del prepubis forman un ángulo de aproximadamente $30^{\circ}$; ésto es debido a que la diáfisis está torsionada de tal modo que su lado ventral se convierte en el lado lateral de la lámina anterior. La diáfisis es plana en sentido dorsoventral, y tiene una sección de 10 × $4 \mathrm{~mm}$; su borde dorsal es redondeado y el ventral afilado (Figs. 7A, D).

El extremo posterior del prepubis está erosionado. En el se observa parte del pedicelo iliaco, que mide en vista dorsal (Fig. 7A) $120 \mathrm{~mm}$ de longitud x $70 \mathrm{~mm}$ de anchura, faltando totalmente el pedicelo isquiático, el postpubis y la zona del foramen obturador. Su superficie lateral es plana y rugosa, la superficie medial es convexa, el borde ventral es afilado y el dorsal convexo. En vistas lateral y posterior (Fig. 7B, E) se observa el acetábulo, de $90 \mathrm{~mm}$ de altura.

Del isquion se conserva la parte proximal, con los pedicelos púbico e iliaco. El fragmento proximal de isquion MPT/I.G.488 fue descrito como isquion de saurópodo (Lapparent, 1960: 190) y siglado como Is ${ }^{\mathrm{s}}$ (Lapparent, 1960: 195). Un fragmento identificado por Lapparent (1960: 195) como neurapófisis $\left(\mathrm{V}^{34}\right)$ es en realidad el pedicelo isquiático del isquion izquierdo (Fig. 5C).

El isquion (Figs. 5C, 8) es plano; conserva una altura de 280 (dorsoventral) $\mathrm{mm}$ y una longitud (anteroposterior) de $350 \mathrm{~mm}$.

En vista lateral se observa el acetábulo (Figs. 5C, 8D), que tiene una superficie rugosa y una forma de $1 / 4$ de círculo. La superficie lateral es plana en sentido dorsoventral y cóncava en sentido anteroposterior (Fig. 8D). La superficie medial es convexa en sentido dorsoventral y cóncava en sentido anteroposterior (Fig. 8C); en ella se observa que el acetábulo mide $150 \mathrm{~mm}$ de longitud por $130 \mathrm{~mm}$ de altura, y que su longitud medida sobre el recorrido del acetábulo es de $210 \mathrm{~mm}$.

En vista proximal (Fig. 8A) se observa el pedicelo isquiático, que es muy rugoso y mide $210 \mathrm{~mm}$ de longitud por $90 \mathrm{~mm}$ de anchura (lateromedial). En vista anterior, el pedicelo púbico mide $105 \mathrm{~mm}$ de altura por $35 \mathrm{~mm}$ de anchura

El isquion no es un hueso recto, en vista distal (Fig. 8B) se observa que el pedicelo iliaco y la diáfisis forman un ángulo de $30^{\circ}$. El pedicelo púbico es delgado y está orientado con el eje mayor de la diáfisis. La sección de la diáfisis mide $90 \mathrm{~mm}$ de longitud (completa se estima que tendría 100) por $50 \mathrm{~mm}$ de anchura, el borde anterior es afilado y el borde posterior redondeado.

\section{Comparación y discusión}

Iguanodontoidea incluye a Hadrosauridae CoPE 1869 y a varios taxones más basales que tradicionalmente se incluían en la familia Iguanodontidae BONAPARTE 1850 (véase Norman, 1980, 1986, 1990, 1996, 1998; Norman \& Weishampel, 1990; Sereno 


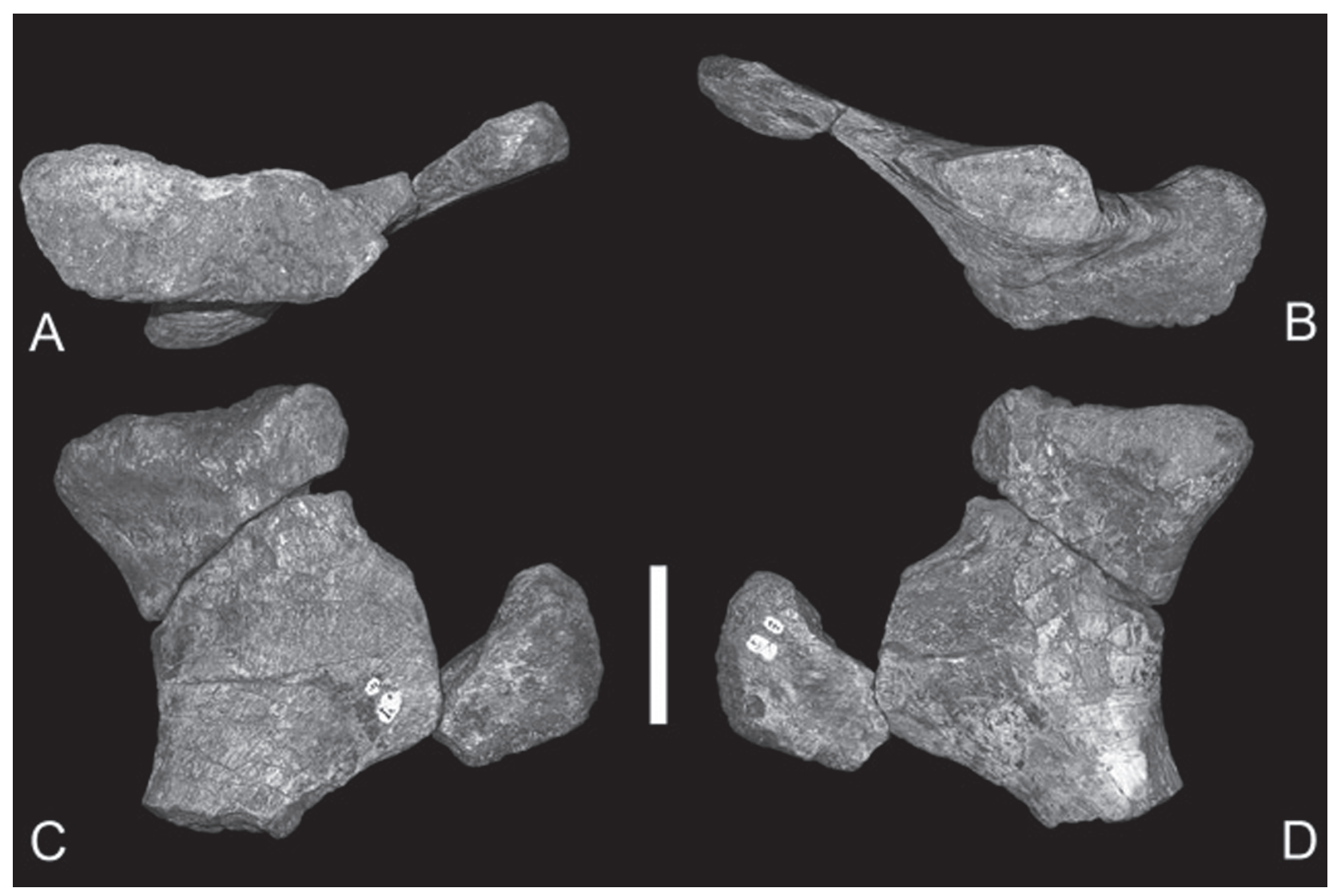

Fig. 8.-Delapparentia turolensis nov. gen. et sp. de La Maca 3, Galve (Teruel, Barremiense inferior). MPT/I.G.488 +MPT/I.G.468( $\left.\mathrm{V}^{34}\right)$ : isquion izquierdo, en vistas proximal (A), distal (B), medial (C) y lateral (D). Escala: $10 \mathrm{~cm}$.

1997, 1998, 1999a, 1999b), considerada parafilética desde hace unos años (véase Head \& Kobayashi, 2001; Norman, 2002, 2004; Kobayashi \& Azuma, 2003), por lo que en este trabajo se usa «iguanodóntido» para referirse a los Iguanodontoidea no Hadrosauridae (sensu Norman, 2002).

Sereno (2005) propone que Iguanodontoidea y Hadrosauriformes SERENo 1997 son sinónimos, y que Hadrosauriformes fue filogenéticamente definido en 1998 (Sereno, 1998) e Iguanodontoidea en 2002 (Norman, 2002) por lo que Hadrosauriformes tiene preferencia; además este autor propone que el uso del sufijo «oidea» indica superfamilia, y una superfamilia no debería contener otra (Iguanodontoidea contiene Hadrosauroidea CoPE 1869). En este trabajo se usa el término Iguanodontoidea siguiendo a Norman $(2002,2004)$ y la familia Hadrosauridae, siguiendo a Horner et al. (2004), en vez de la superfamilia Hadrosauroidea. Norman (2002) define Iguanodontoidea como «Iguanodon y todos los iguanodontios más estrechamente relacionados con Edmontosaurus que con Camptosaurus».
Las vértebras de Delapparentia no son diagnósticas más allá de Ornithopoda. Son muy parecidas a las de Iguanodon como ya destacó Lapparent (1960). El sacro tiene una superficie ventral quillada, sin surco, diferente del sacro de I. bernissartensis que sí que lo posee (Norman, 1980, 1986). Según Norman (1998: 346) el carácter «surco ventral en el sacro» de Weishampel et al. (1993), presente en Ouranosaurus y lambeosaurinos, está sujeto a paralelismo en los ornitópodos no hadrosáuridos: Mantellisaurus tiene el sacro con quilla y surco (Norman, 1986: fig. 35, como I. atherfieldensis), e I. bernissartensis tiene sacras posteriores con un amplio surco (Norman, 1980).

Las costillas dorsales, en cambio, presentan características no descritas en otros ornitópodos: costillas dorsales anteriores con un foramen neumático debajo del tubérculo, y costillas dorsales posteriores con capítulo y tubérculo alargados, paralelos, con una hendidura intermedia y fusionados proximalmente.

Además se han identificado costillas esternales osificadas. La presencia de «segmentos esternales 
de las costillas dorsales anteriores parcialmente osificados» es una sinapomorfía de Hypsilophodontidae según Sereno (1986), Forster (1990), Weishampel \& Heinrich (1992) y Sues (1997). Weishampel et al. (2003: carácter 40) no reconocen la familia Hypsilophodontidae pero sí que reconocen que hay osificación parcial de los segmentos esternales de las costillas en Thescelosaurus GILMORE 1913, Parksosaurus STERnBerg 1937 e Hypsilophodon HuXLey 1869. Calvo et al. (2007: carácter 11) citan costillas esternales osificadas en tres ornitópodos basales: el elasmario Macrogryphosaurus, y los hypsilofodóntidos Thescelosaurus e Hypsilophodon (nótese que estos autores consideran válida la familia Hypsilophodontidae).

Estos tres caracteres de las costillas dorsales son autapomorfías de Delapparentia turolensis (la tercera convergente con los hypsilofodóntidos y Macrogryphosaurus).

El material más diagnóstico del «iguanodóntido» de La Maca 3 es la cadera, y sobre todo el ilion, con su proceso preacetabular torsionado y en posición horizontal.

La presencia de prepubis aplanado lateromedialmente y expandido dorsoventralmente (Figs. 7B, C, F) incluye a Delapparentia dentro del clado Iguanodontoidea:

Norman (1990) considera que «Camptosaurus + “higher» ornithopods» (=Ankylopollexia de Sereno, 1986) tienen un prepubis transversalmente aplanado y alto sin expansión distal (nodo 2, carácter 4) y que «Iguanodontidae [Iguanodon + Ouranosaurus] + Probactrosaurus RoZHDESTVENSKY 1966 + Hadrosauridae» (equivalente a Styracosterna de Sereno, 1986) tienen el prepubis expandido distalmente (nodo 3, carácter 4) y un postpubis reducido (nodo 2 , carácter 54). La reducción del postpubis no puede observarse en Delapparentia, pero el prepubis está expandido distalmente, por lo que quedaría incluido dentro del «nodo 3» de Norman (1990).

Según Godefroit et al. (1998: carácter 4), el prepubis expandido dorsoventralmente y separado por un cuello es propio del «nodo 2» (Iguanodon + Ouranosaurus + Hadrosauroidea), que equivale a Iguanodontoidea.

Norman (2002: 138, apéndice 2, carácter 58) considera la expansión de la lámina prepúbica como un carácter de Iguanodontoidea (Iguanodon + Ouranosaurus + Altirhinus NORMAN $1998+$ Eolambia KIRKLAND 1998 + Protohadros HEAD 1998 + Probactrosaurus + Hadrosauridae), carácter que también aparece en Lurdusaurus TAQUET et RUSSEL 1999
(Norman, 2002: apéndice 1, carácter 58) [nótese que este autor excluye a Lurdusaurus de Iguanodontoidea, aunque posteriormente (Norman, 2004) lo incluye]. Norman (2004: 434) considera la presencia de «proceso prepúbico aplastado lateralmente» en el pubis como un carácter de Iguanodontoidea, aunque no lo incluye en el análisis cladístico (Norman (2004: información suplementaria).

El ilion de Delapparentia carece de antitrocánter (Fig. 6C), estructura que se desarrolla en los hadrosáuridos (Horner et al., 2004: 456), por lo que Delapparentia no es un hadrosáurido:

Godefroit et al. (1998: carácter 20) consideran el antitrocánter como derivado y presente en Hadrosauroidea (Bactrosaurus GILMORE 1933 + Telmatosaurus NOPCSA 1903 + Hadrosaurinae + Lambeosaurinae). Estos autores consideran que Bactrosaurus y Telmatosaurus no pertenecen a Hadrosauridae, pero Horner et al. (2004) sí que los incluyen en Hadrosauridae. Por lo tanto, el concepto de Hadrosauroidea de Pascal Godefroit y colaboradores coincide con el de Hadrosauridae de Horner y colaboradores.

Head \& Kobayashi (2001: 111) consideran la presencia de antitrocánter en el ilion como derivado (carácter 20; ausente en Eolambia, Iguanodon y Ouranosaurus, presente en Altirhinus, Gilmoreosaurus BRETT-SuRman 1979, Bactrosaurus, Hadrosaurinae y Lambeosaurinae, desconocido en «Fukui form» [= Fukuisaurus KoBAYASHI et AzUMA 2003], Probactrosaurus, Protohadros y Telmatosaurus).

Norman (2002: apéndices 1 y 2, carácter 56) considera que el borde dorsal del ilion «muy prominente y con un proceso pendiente» aparece sólo en los euhadrosaurios (sensu Weishampel et al., 1993; = Hadrosaurinae + Lambeosaurinae).

Horner et al. (2004: 456) consideran la presencia de «proceso supracetabular (=antitrocánter) grande y colgante» en el ilion como un carácter de Hadrosauridae, aunque no lo incluyen en el análisis cladístico (Horner et al., 2004: información suplementaria).

Estas dos características del prepubis y el ilion de Delapparentia permiten llegar a la conclusión de que pertenecen a un Iguanodontoidea no Hadrosauridae, o lo que se denomina informalmente un «iguanodóntido». A continuación se compara la cadera (ilion, isquion y pubis) de Delapparentia turolensis con la de los «iguanodóntidos» de los que se conoce la cadera.

El Apéndice 2 recoge un listado de las especies válidas de iguanodontoideos no hadrosáuridos des- 
critas en el Cretácico Inferior, basado en Norman (2004) con actualizaciones de nuevos taxones y reinterpretaciones posteriores de algunos de ellos (Godefroit et al., 2005; You et al., 2005; Brill \& Carpenter 2007; Gilpin et al., 2007; Paul, 2007, 2008; Carpenter \& Wilson, 2008; Galton, 2009; You \& Li, 2009; McDonald et al., 2010).

Además Norman (2004) cita tres géneros en el Cretácico Superior: Craspedodon Dollo 1883, Protohadros HeAD 1998 y Shuangmiaosaurus You, Ji, Li et Li 2003a. Recientemente, Godefroit \& Lambert (2007) han reestudiado Craspedodon, del Santoniense de Bélgica («glauconie argileuse»), que se conoce sólo por tres dientes aislados, al que consideran un neoceratopsio y no un ornitópodo. Protohadros, del Cenomaniense de Texas, Estados Unidos (Formación Woodbine, Miembro Arlington), descrito inicialmente como un hadrosáurido y posteriormente considerado un iguanodontoideo no hadrosáurido (Head, 2001), se conoce por un cráneo, el atlas, fragmentos de costilla y una falange de la mano (Head, 1998), que no permiten comparación con Delapparentia. Shuangmiaosaurus, del Cenomaniense-Turoniense de Liaoning, China (Formación Sunjiawan; Dong, 2002) se conoce sólo por material craneal (You et al., 2003a), que no permite comparación con Delapparentia.

No se conoce, o no se ha descrito, la cadera de todos los iguanodontoideos no hadrosáuridos mencionados en el Apéndice 2. Dakotadon Paul 2008, Kukufeldia, Owenodon, Jintasaurus You et LI 2009, Penelopognathus Godefroit, Li et SHANG 2005 y Theiophytalia BRILl et CARPENTER 2007 están basados únicamente en material craneal (Weishampel \& Bjork, 1989; Godefroit et al. 2005; Brill \& Carpenter, 2007; Paul, 2008; You \& Li, 2009; Galton, 2009; McDonald et al., 2010), y Fukuisaurus en material craneal y una placa esternal (Kobayashi \& Azuma, 2003), por lo que el material no es comparable con el de Delapparentia. I. anglicus está basado en dientes aislados (véase Paul, 2008), e I. orientalis en premaxilar, maxilar, nasal, escápula y fragmentos de arcos neurales dorsales, costillas y metatarsales (Norman, 1996) que no permiten comparar con el material de Delapparentia.

Iguanodon ottingeri, descrito a partir de un fragmento de maxilar con dientes (Galton \& Jensen, 1979), es un nomen dubium según Weishampel \& Bjork (1989) y Norman (2004). De él se ha encontrado posteriormente abundante material que, por el momento, no se ha descrito, destacando sus espinas neurales dorsales muy altas («tall-spined iguanodontid»; Scheetz et al., 2010). La cadera de Jinzhousaurus WANG et XU 2001, al igual que todo el esqueleto postcraneal, no ha sido descrita (Wang \& $\mathrm{Xu}, 2001)$. De Nanyangosaurus XU, ZHAO, LU, HuAng, Li et Dong 2000 sólo se conserva la extremidad distal del isquion (Xu et al., 2000) que no sirve para comparar con Delapparentia.

La cadera de Delapparentia puede compararse con las de Altirhinus kurzanovi, Barilium dawsoni, Dollodon bambingi, Cedrorestes crichtoni, Eolambia caroljonesa, Equijubus normani, Hypselospinus fittoni, Iguanodon bernissartensis, Jinzhousaurus yangi, Lanzhousaurus magnidens, Lurdusaurus arenatus, Mantellisaurus atherfieldensis, «Mandschurosaurus» laosensis, Muttaburrasaurus langdoni, Ouranosaurus nigeriensis, Planicoxa depressa, Planicoxa venenica, Probactrosaurus alashanicus, Probactrosaurus gobiensis, «Probactrosaurus» mazongshanensis y Vectisaurus valdensis.

El holotipo de Altirhinus kurzanovi tiene pubis e isquion, pero no ilion (Norman, 1998: 297), aunque hay un pequeño ilion asignado a $A$. kurzanovi que procede del mismo yacimiento que el holotipo (Norman, 1998: 329). El ilion (Norman, 1998: fig. 32) tiene el borde posterodorsal de la lámina iliaca saliente (everted, antitrochanter-like) y un proceso anterior (roto) curvado ventralmente y reforzado medialmente por una cresta prominente que confluye con el área sutural para el sacro. El proceso anterior curvado y el antitrocánter lo diferencian de Delapparentia [nótese que Head (2001: apéndice 2: carácter 24) dice que Altirhinus no tiene antitrocánter, aunque Head \& Kobayashi (2001: apéndice 1, carácter 21) dicen que Altirhinus sí tiene antitrocánter prominente].

El ilion de Barilium dawsoni (Lydekker, 1888: fig. 2; Norman, 1987: fig. 4; Paul, 2008: fig. 3B-a; Norman, 2010: fig. 3) tiene el proceso preacetabular roto; el borde dorsal del ilion es convexo, por lo que el proceso preacetabular se curvaría ventralmente (véase reconstrucción en Blows, 1998: fig. 3A, basada en el holotipo, NHMUK R802, y una pelvis referida, NHMUK R3788). El pubis es muy fragmentario y no permite comparaciones con el de Delapparentia. El isquion es similar al de I. bernissartensis, D. bampingi y $M$. atherfieldensis y también al fragmento conservado en Delapparentia (Figs. 5C, 8).

La cadera de Dollodon bambingi, fue descrita y figurada por Norman (1986: figs. 53, 55A, 56A) como I. atherfieldensis. Paul (2008: tabla 1) propor- 
ciona una diferencia entre las caderas de los holotipos de $D$. bambingi [IRSNB 1551] y $M$. atherfieldensis [NHMUK R5764]: el ilion del primero es bajo (como en I. bernissartensis y los hadrosaúridos) mientras que el del segundo es alto. En ambas especies el proceso preacetabular es largo y se curva ventralmente (Norman, 1986: fig. 53A; Paul, 2008: fig. 3B-f, k) diferenciándose de Delapparentia. El prepubis en ambas especies es similar (Norman, 1986: fig. 55A, B; Paul, 2008: fig. 3C-e, f) y difiere de Delapparentia en ser más corto y más expandido anteriormente.

En la Formación Cedar Mountain de Utah (Estados Unidos) hay restos de tres «iguanodóntidos» distintos cuyos iliones se han conservado: Cedrorestes Gilpin, DiCRoce et CARPENTER 2007, Eolambia y Planicoxa Dicroce et CARPENTER 2001 (Apéndice 2). Planicoxa está también presente en la Formación Lakota (Barremiense) de Dakota del Sur (Estados Unidos; P. depressa).

Cedrorestes ha sido descrito como un hadrosáurido (Carpenter et al., 2002; Gilpin et al., 2002, 2007) aunque Butler (2008) dice que podría no serlo. El ilion tiene proceso postacetabular, antitrocánter y «notch» postacetabular, como los hadrosáuridos (Gilpin et al., 2002, 2007). El proceso preacetabular se curva muy poco ventralmente (Gilpin et al., 2002), aunque su extremo anterior está roto (Carpenter et al., 2002: fig. 8; Gilpin et al., 2007: figs. 5.3C, 5.4A). En cualquier caso el ilion tiene «antitrocánter» (Carpenter et al., 2002: fig. 8; Gilpin et al., 2007: figs. 5.3C, 5.4) por lo que se diferencia del de Delapparentia.

De Eolambia caroljonesa hay restos de los tres huesos de la cadera, aunque los del pubis (mencionados por Maxwell \& Cifelli, 2002) no han sido descritos. El ilion y el isquion han sido descritos por Kirkland (1998) y Head (2001). Según la diagnosis de Eolambia (Kirkland, 1998: 286) el ilion tiene un proceso preacetabular ligero un antitrocánter pobremente desarrollado y un brevis shelf bien desarrollado. En la descripción del único ilion disponible en ese momento (OMNH 04213, juvenil; Kirkland, 1998: 289) se dice además que el proceso preacetabular es largo y que el antitrocánter (=cresta suprailiaca) es sólo incipiente. En el carácter 41 (antitrocánter grande en el ilion) de la matriz de caracteres de Kirkland (1998: tabla1), Iguanodon, Ouranosaurus y Probactrosaurus tienen un 0 , Eolambia, Gilmoreosaurus y Bactrosaurus un 1, y los hadrosáuridos un 2 [sin embargo, Kirkland (1998: apéndice 1), considera que Eolambia es pri- mitivo para este carácter, y no se especifica cuales son los estados 1 y 2].

Head (2001: 392) considera que el ilion de Eolambia es muy característico por tener un acetábulo extremadamente grande, más que el de ningún estado ontogenético de otros iguanodontios. Además destaca que el proceso preacetabular es largo y curvado ventralmente y el borde dorsal está expandido y rugoso; se expande lateralmente desde la altura del borde posterior del pedicelo púbico hasta el borde posterior del ilion para la inserción de la musculatura aductora de la pierna. Se diferencia de otros iliones en carecer de región postacetabular por detrás del pedicelo isquiático. Por la figuración de Head (2001: fig. 2B, C) pudiera ser que el borde ventral del ilion estuviera roto y no se conservara el acetábulo y la parte posterior del ilion; en esta figura se observa que el proceso preacetabular es delgado en sentido lateromedial y está expandido dorsoventralmente, al contrario que en Delapparentia.

Carpenter et al. (2002: fig. 7) figuran un ilion que asignan a Eolambia y que es diferente al ilion OMNH 04213 figurado por Kirkland (1998: fig. 10) y Head (2001: fig. 2B-C) [perteneciente a un esqueleto juvenil parcial, uno de los paratipos; Kirkland, 1988: 286] al ser mucho más expandido dorsoventralmente. Quizá las diferencias sean debidas a la ontogenia o a que se tratan de dos taxones diferentes.

De Planicoxa venenica se conoce el ilion, que además es el holotipo (DiCroce \& Carpenter, 2001), y que se diferencia de Delapparentia en la presencia de un proceso postacetabular dirigido horizontalmente, y un proceso preacetabular largo (mitad de la longitud total) y curvado ventralmente (DiCroce \& Carpenter, 2001: fig. 13.5; Carpenter \& Wilson, 2008: fig. 49F-H).

De Planicoxa depressa se conocen el ilion y el pubis (Gilmore, 1909; Weishampel \& Bjork, 1989; Carpenter \& Wilson, 2008). El pubis no ha sido figurado, únicamente Gilmore (1909: 293) menciona en la diagnosis de la especie Camptosaurus depressus GILmore 1909: «Extremo anterior del pubis ancho». El ilion ha sido figurado por (Gilmore, 1909: figs. 45, 46) y Carpenter \& Wilson, 2008: fig. 49A-E). Al igual que en el caso de P. venenica, la presencia de un proceso preacetabular largo y curvado ventralmente, y sobre todo de un proceso postacetabular horizontal (Carpenter \& Wilson, 2008: fig. 49C-D) lo diferencian de Delapparentia.

Equijubus You, Luo, Shubin, Witmer, TANg et TANG 2003b fue definido como un Hadrosauroidea 
basal (grupo hermano de Probactrosaurus + Bactrosaurus + Protohadros + Telmatosaurus + Hadrosauridae; You, 2002, You et al., 2003b). Sin embargo, Norman (2002) considera que Equijubus [como «Mazongshan sp.»] y Lurdusaurus son el grupo hermano de Iguanodon + Ouranosaurus + Altirhinus + Eolambia + Protohadros + Probactrosaurus + Hadrosauridae (que incluye a Telmatosaurus y Bactrosaurus), y Norman (2004: 425) lo lista dentro de Iguanodontoidea, aunque en su figura 19.21 aparece como el grupo hermano de Iguanodontoidea en una posición cercana a Camptosaurus. De Equijubus se conocen los iliones (You, 2002: 46), que no han sido descritos aunque You (2002: fig. 3.3) y You et al. (2003b: fig. 2) figuran el ilion izquierdo en vista lateral. Sorprendentemente, You (2002: apéndice 2) y You et al. (2003b: tablas 2 y 3) utilizan seis caracteres del ilion en su análisis cladístico, pero le dan valores desconocidos (?) a Equijubus. Aparentemente, el ilion de Equijubus tiene el borde dorsal convexo y hay un antitrocánter incipiente. Aunque está roto anteriormente, el proceso preacetabular se curvaría ventralmente (You, 2002: fig. 3.3; You et al., 2003b: fig. 2).

El ilion de Hypselospinus fittoni (NHMUK R1635, que es el holotipo) se caracteriza por un «proceso preacetabular [que] meramente forma una lámina vertical delgada» (Lydekker, 1889: 354) y por una porción postacetabular terminada en punta, no observable en el ilion de Delapparentia. El ilion holotipo ha sido figurado por Lydekker (1890: fig. 1C), Norman (1987: fig. 5), Paul (2008: fig. 3B-a) y Norman (2010: fig. 5), y una reconstrucción basada en el holotipo y un ilion referido (NHMUK R1834) ha sido figurada por Blows (1998: fig. 3B). El isquion referido a este taxón es muy fragmentario, y no diagnóstico más allá de ornitópodo (Norman (2010: fig. 6F).

Iguanodon bernissartensis es la especie tipo de Iguanodon (véase Paul, 2007, 2008), y de ella se conserva la cadera completa (Norman, 1980: figs. 63-67). I. bernissartensis se diferencia claramente de Delapparentia en que el proceso preacetabular del ilion se curva mucho ventralmente (Paul, 2008: fig 3B-c).

El prepubis de Delapparentia es más similar al de I. bernissartensis que al de $M$. atherfieldensis y $D$. bampingi, aunque está más expandido dorsoventralmente en Delapparentia. Según Norman (1986: 327) I. bernissartensis tiene siete autapomorfías que lo diferencian de I. atherfieldensis [que ahora incluye a $M$. atherfieldensis y $D$. bampingi, después de las revisiones de Paul (2007, 2008)]. Entre ellas está «pubis con la parte proximal de la caña del proceso anterior estrecha (vii)», lo que también ocurre en Delapparentia (compárense las Figs. 5B y 7B con las figuras de Norman para I. bernissartensis (Norman, 1980: fig. 64) y D. bampingi (Norman 1986: figs. 53, 55, como I. atherfieldensis), y las figuras de Paul para I. bernissartensis, M. atherfieldensis y D. bampingi (Paul, 2007: fig. 4.2G, I, 2008: fig. 3C-b, e, f,).

De Lanzhousaurus You, Ji et Li 2005 se conoce sólo el pubis, que no ha sido descrito en detalle. Únicamente, You et al. (2005) dicen que es típico de los estiracosternos (=iguanodontoideos, véase más arriba), con un proceso prepúbico alto, y que es más similar a las formas basales como Iguanodon que a las formas derivadas como Probactrosaurus, con un prepubis relativamente largo y con la parte proximal estrechada. El pubis de Lanzhousaurus es muy parecido al de Dollodon y Mantellisaurus, corto y alto (compárese Norman, 1986: fig. 55 con You et al., 2005: fig. 3C), y diferente al de I. bernissartensis (Norman, 1980: fig. 65) y al de Delapparentia, más alargados.

De Lurdusaurus arenatus sólo se ha publicado una descripción preliminar (Taquet \& Russel, 1999), aunque existe una Tesis Doctoral en la que se describe todo el material (Chabli, 1988). Taquet \& Russel (1999: lám. 3, figs. 1, 2) figuran los dos pubis de Lurdusaurus, que se asemejan al del Delapparentia y a los de Iguanodon bernissartensis al ser relativamente alargados (respecto a otros taxones, como Dollodon o Mantellisaurus).

Chabli (1988: figs. 23A, 24, 25A, 26, 27A, láms. 12-14) figura el ilion, isquion y pubis de L. arenatus [al que denomina «Gravisaurus tenerensis»]. El ilion (Chabli, 1988: fig. 23A, láms. 12-14) tiene el proceso preacetabular corto y curvado ventralmente, diferenciándose del ilion de Delapparentia; además Lurdusaurus tiene una protuberancia cónica en el borde posterodorsal (origen del «Músculo dorsocaudal», según Chabli, 1988: 71) que no aparece en Delapparentia. El pubis tiene un proceso postpúbico muy corto respecto a otros taxones (carácter destacado por Taquet \& Russel, 1999: 90), pero esta parte no está conservada en el pubis de Delapparentia, por lo que no puede realizarse una comparación.

Como ya se ha visto al hablar de la cadera de Dollodon bampingi e Iguanodon bernissatensis, la cadera de Mantellisaurus atherfieldensis difiere de la de Delapparentia en tener un proceso preacetabular del ilion curvado ventralmente y un prepubis 
más corto y más expandido anteriormente (Norman, 1986: fig. 55B; Paul, 2008: figs. 3B-f, 3C-e).

«Mandschurosaurus» laosensis fue considerado un hadrosáurido en su descripción original (Hoffet, 1944a). Ha sido asignado después a Hadrosauridae indet. (Weishampel, 1990) y a cf. Gilmoreosaurus (Buffetaut, 1991) por por su parecido con el hadrosáurido Gilmoreosaurus mongoliensis (GILMORE 1933). Posteriormente ha sido considerado como un «iguanodóntido» (Taquet et al., 1992; Buffetaut \& Suteerthorn, 1998a, 1998b, 1998c) y un Iguanodontia indet. (Weishampel et al., 2004). Weishampel \& Horner (1990) y Horner et al. (2004) lo listan como nomen dubium. La edad de «Mandschurosaurus» laosensis ha sido considerada como Cretácico Superior (Campaniense, Hoffet, 1944b; Coniaciense-Maastrichtiense, Weishampel, 1990); Cretácico Inferior-Cretácico Superior basal (Buffetaut, 1991), Cretácico Inferior (Taquet et al., 1992) y AptienseAlbiense (Buffetaut \& Suteethorn, 1998a, 1998b, 1998c; Weishampel et al., 2004).

De «Mandschurosaurus» laosensis se conoce un ilion, que es uno de los sintipos (Hoffet, 1944a); el resto del material tipo (tres extremidades distales de fémur, escápula) no es comparable con Delapparentia. El ilion de «M.» laosensis tiene un proceso preacetabular muy largo y curvado ventralmente; se diferencia de Delapparentia por presentar un reborde dorsal a lo largo de toda la lámina iliaca (Hoffet, 1944a: fig. 3). Un ilion del mismo yacimiento asignado a «Hadrosaure non identifié» se diferencia de «M.» laosensis en tener el proceso preacetabular recto, delgado y con una cresta longitudinal interna. Delapparentia carece de esta cresta y tiene el proceso preacetabular expandido lateromedialmente.

Muttaburrasaurus langdoni fue descrito originalmente como un Iguanodontoidea (Bartholomai \& Molnar, 1981), aunque en un trabajo posterior fue considerado como un ornitópodo más basal que Tenontosaurus Ostrom 1970 (Molnar, 1996). Norman (2004: tabla 19.1) lista M. langdoni como un Iguanodontoidea, pero después lo considera un Iguanodontia no Dryomorpha, intermedio entre Tenontosaurus y Zalmoxes (Norman, 2004: 434, fig. 19.21). Recientemente, Calvo et al. (2007) lo consideran como un Iguanodontia basal, por debajo de Dryomorpha. Independientemente de su posición filogenética, el proceso preacetabular del ilion, aunque incompleto, se curva ventralmente (Bartholomai \& Molnar, 1981: fig. 8), diferenciándose del de Delapparentia. Además el prepubis no está expandido dorsoventralmente (Molnar, 1996: 649, contra Bartholo- mai \& Molnar, 1981: 334) al igual que ocurre en Tenontosaurus y Zalmoxes (Ostrom, 1970; Weishampel et al., 2003; Godefroit et al., 2009) por lo que, de acuerdo a este carácter, Muttaburrasaurus BARTHOLOMAI et MOLNAR 1981 no sería un iguanodontoideo.

La cadera de Ouranosaurus nigeriesis, completa y bien conservada, ha sido descrita y figurada en detalle por Taquet (1976: figs. 58-61, lám. 23). El ilion tiene un proceso preacetabular relativamente más largo que en Delapparentia y curvado ventralmente, y el pubis presenta un proceso prepúbico relativamente más corto.

De Probactrosaurus gobiensis se conoce la cadera completa (Norman, 2002: figs. 27-29). Aunque Rozhdestvensky (1967) encuentra diferencias entre P. gobiensis y P. alashanicus, entre otras cosas en la cadera, Norman (2002: 137) considera ambas especies sinónimas [aunque Norman (2004: 417) las vuelve a listar como especies diferentes].

Según la diagnosis de Rozhdestvensky (1967: 557), Probactrosaurus tiene «ilion con proceso anterior estrecho, ligeramente curvado, con longitud aproximadamente 1.5 veces la base del hueso y proceso posterior con forma de lóbulo triangular», «prepubis con borde inferior horizontal y borde superior fuertemente convexo, con anchura máxima alrededor de un tercio de su longitud» e «isquion recto». Según la diagnosis de Norman (2002: 117), Probactrosaurus tiene "proceso anterior del ilion alargado y horizontal; lámina prepúbica alta y distalmente expandida; isquion robusto, curvado y con «pie», con un proceso obturador triangular grande y en posición proximal».

En estas diagnosis hay ciertas diferencias que pueden basarse en los ejemplares en los que se basen [hay al menos dos esqueletos parciales y numerosos huesos aislados (Norman, 2002: 116), y los restos de $P$. gobiensis y $P$. alashanicus proceden de dos niveles fosilíferos diferentes (Rozhdestvensky, 1967: $558,560)]$ o en apreciaciones subjetivas. La forma del proceso preacetabular es recta según Norman y ligeramente curvada según Rozhdestvensky (opinión que suscribe el autor de este artículo viendo las figuraciones de los iliones que proporciona Norman, 2002: fig. 27). Sea o no este proceso anterior curvado, tanto el ilion como el pubis de Probactrosaurus se diferencian de los de Delapparentia:

- Aunque Rozhdestvensky (1967: 558) considera que Probactrosaurus tiene ilion con antitrocánter ausente o poco desarrollado, tanto P. gobiensis (Norman, 2002: fig. 27A, C) como P. alashanicus (Nor- 
man, 2002: fig. 27B) tienen ilion con antitrocánter, diferenciándose del ilion de Delapparentia;

- Además el pubis de Probactrosaurus (Norman, 2002: fig. 28) es muy corto, similar al de Dollodon bambingi y Mantellisaurus atherfieldensis (Norman, 1986: fig. 55A, B; Paul, 2008: fig. 3Ce, f) y diferente al de Delapparentia.

Probactrosaurus mazongshanensis no es referible al género Probactrosaurus (Norman, 2002) por lo que en este trabajo se denomina «P.» mazongshanensis. De «Probactrosaurus» mazongshanensis se conocen el ilion y el pubis, pero sólo éste último ha sido brevemente descrito aunque no figurado ( $\mathrm{Lu}$, 1997). El pubis de «Probactrosaurus» mazongshanensis es alto y moderadamente expandido, como el de Ouranosaurus, sin constricción en su parte media (Lu, 1997: 42), diferenciándose del de Delapparentia (Figs. 5B, 7).

El holotipo de Vectisaurus valdensis (NHMUK R2494-R2500), considerado como sinónimo de Mantellisaurus atherfieldensis por Norman \& Weishampel (1990) y Norman (2004), incluye un ilion parcial que ha sido descrito y figurado por varios autores (Hulke, 1879: lám 21, fig. 1; Galton, 1976: fig. 1N-P; Norman, 1990: fig. 11.2, 11.3B, como Iguanodon juvenil; Paul, 2008: fig. 3B-j, como Mantellisaurus sp.). El proceso preacetabular se curva ventralmente sólo ligeramente, pero no se torsiona y expande lateromedialmente, como en Delapparentia, sino que está comprimido lateromedialmente. Un esqueleto parcial NHMUK R8649, referido a $V$. valdensis por Galton (1976), incluye una pareja de iliones que sí tienen el proceso preacetabular curvado ventralmente y comprimido lateromedialmente (Galton, 1976: fig. 2A-D; Norman, 1990: figs. 11.4, 11.5), como en Mantellisaurus atherfieldensis y Dollodon bampingi.

Tras la comparación con otros «iguanodóntidos» de los que se ha descrito y/o figurado la cadera, se ha visto que la cadera del «iguanodóntido» de La Maca 3 es diferente de las de los demás por tener el proceso preacetabular torsionado, expandido lateromedialmente y en posición horizontal, y por tener un isquion de tamaño grande respecto al ilion, por lo que no pertenece a Iguanodon bernissartensis sino a un nuevo género y especie.

La presencia de I. bernissartensis en Galve había sido citada en muchos trabajos de difusión internacional, sobre todo aludiendo a los trabajos de Lapparent de 1960 y de Sanz y colaboradores de 1984 (Norman, 1980, 1996, 1998, 2004; Weishampel \&
Bjork, 1989; Norman \& Weishampel, 1990; Weishampel, 1990; Glut, 1997; Weishampel et al., 2004) [Norman \& Weishampel (1990: Tabla 25.1) y Weishampel (1990: 102) citan erróneamente la formación Camarillas como «Las Zabacheras Beds», y Norman (2004: Tabla 19.1) y Weishampel et al. (2004: 561) citan erróneamente los taxones de la Formación Camarillas en Galve como provincia de La Rioja]. A partir de este trabajo queda descartada la existencia de I. bernissartensis en Galve.

El esqueleto del «iguanodóntido» de La Maca 3 se asigna a Delapparentia turolensis nov. gen. et sp., que está caracterizado por las siguientes autapomorfías: 1) costillas dorsales posteriores con capítulo y tubérculo alargados, paralelos, con una hendidura intermedia y fusionados proximalmente, 2) costillas esternales osificadas (convergente con Hypsilophodontidae y Macrogryphosaurus; Weishampel \& Heinrich, 1992; Calvo et al., 2007), 3) ilion con el proceso preacetabular torsionado, expandido lateromedialmente y en posición horizontal (compartido con Zalmoxes, Weishampel et al., 2003; Godefroit et al., 2009). Además presenta costillas dorsales anteriores con un foramen neumático, y un isquion de tamaño grande respecto al ilion.

Weishampel et al. (2003) consideran el proceso preacetabular torsionado como una autapomorfía de Zalmoxes, puesto que no aparece en ninguno de los taxones incluidos en su análisis (Weishampel et al, 2003: carácter 56, apéndice 4 [véase también McDonald et al., 2010: carácter 110, apéndices 2 y 3]. Se trata de un carácter que ha evolucionado al menos dos veces en los ornitópodos, una dentro de Rhabdodontidae WeIshampel, JIANU, CZIKI et NoRMAN 2003 (Zalmoxes), y otra dentro de Iguanodontoidea (Delapparentia).

\section{Conclusiones}

El material más diagnóstico del ornitópodo de La Maca 3 es la cadera. Se ha identificado como un «iguanodóntido» (i.e. un Iguanodontoidea no Hadrosauridae) por la presencia de lámina prepubica alta y la ausencia de antitrocánter en el ilion.

La cadera del «iguanodóntido» de La Maca 3 es diferente de las de otros «iguanodóntidos» por tener el proceso preacetabular torsionado, expandido lateromedialmente y en posición horizontal, y por tener un isquion de tamaño grande respecto al ilion.

Por tanto, los restos del «iguanodóntido» de La Maca 3 no pertenecen a I. bernissartensis como pro- 
puso Lapparent (1960) y mencionaron autores posteriores, sino que corresponde a un nuevo género y especie de Iguanodontoidea, Delapparentia turolensis nov. gen. et sp. Este nuevo taxón se caracteriza además por la presencia de costillas esternales osificadas, costillas dorsales anteriores con un foramen neumático, y costillas dorsales posteriores con capítulo y tubérculo alargados, paralelos, con una hendidura intermedia y fusionados proximalmente.

\section{Nota añadida en prensa}

Mientras este manuscrito se encontraba en prensa algunas de las especies con las que se compara Delapparentia turolensis nov. gen. et sp. (apartado de Comparación y discusión y Apéndice 2) han sido asignadas a nuevos géneros (Carpenter \& Ishida, 2010; McDonald, 2011):

- El esqueleto parcial NHMUK R8649, citado en el texto como Vectisaurus valdensis, es ahora el holotipo de Proplanicoxa galtoni Carpenter et Ishida 2010.

- El esqueleto parcial NHMUK R3788, referido en el texto a Barilium dawsoni, es ahora el holotipo de Sellacoxa pauli Carpenter et Ishida 2010.

- Planicoxa depressa se asigna a Osmakasaurus depressus (Gilmore 1909).

\section{AGRADECIMIENTOS}

Este trabajo forma parte de la Tesis Doctoral del autor, que fue codirigida por los doctores José Ignacio Canudo y Gloria Cuenca-Bescós (Universidad de Zaragoza), y defendida ante el tribunal formado por los doctores Nieves López-Martínez (Universidad Complutense de Madrid), Marc Aurell (Universidad de Zaragoza), $\mathbf{M}^{\mathrm{a}}$ Lourdes Casanovas (Institut Paleontologic «Miquel Crusafont», Sabadell), José Carlos García-Ramos (Universidad de Oviedo) y Xabier Pereda-Suberbiola (Universidad del País Vasco); agradezco a todos ellos el haber sido, a su manera, los primeros revisores de este trabajo. Las siguientes personas facilitaron el acceso al material estudiado: Eduardo Espílez y Rafael Royo-Torres (FCPT-D), Carmen Escriche y Jaime Vicente (MPT), José María Herrero (MPG), José Antonio Gámez-Vintaned (MPZ), y Ángela Buscalioni y José Luis Sanz (UAM). La preparación de los materiales fue realizada en los laboratorios de Paleoymás S.L.L. (Zaragoza) y la Fundación Conjunto Paleontológico de Teruel-Dinópolis (Teruel). El estudio del material se realizó con sendas becas predoctorales del Instituto de Estudios Turolenses (1994-1995) y del Gobierno de Aragón (CONSID, 1995-1998). El Ayuntamiento de Galve, el Gobierno de Aragón, y la Diputación Provincial de Teruel prestaron ayuda económica y/o personal en las prospecciones y estancias de investigación realizadas en Galve. La investigación en el Museo del Jurásico de Asturias (MUJA) está subvenciona- da por el Protocolo de colaboración CN-04-226 entre la Consejería de Cultura y Turismo del Principado de Asturias y la Universidad de Oviedo. Este trabajo es una contribución al proyecto CGL2007-62469/BTE del Ministerio de Ciencia e Innovación. Agradecezco a Rodolfo Coria (CONICET-Museo Carmen Funes, Plaza Huincul, Argentina) y a un revisor anónimo sus sugerencias, que han contribuido a mejorar sustancialmente la calidad de este trabajo, y a José María Cebriá (Museo Nacional de Ciencias Naturales, CSIC, Madrid) la labor editorial.

\section{Referencias}

Alcalá, L. (2005). Albert F. de Lapparent y los dinosaurios de Teruel. Boletín de la Comisión de Historia de la Geología de España (SGE), 26: 4-6.

Bartholomai, A. \& Molnar, R.E. (1981). Muttaburrasaurus, a new iguanodontid (Ornithischia: Ornithopoda) from the Lower Cretaceous of Queenslad. Memoirs of the Queensland Museum, 20: 319-349.

Blows, W.T. (1998). A review of Lower and Middle Cretaceous dinosaurs of England. In: Lower and Middle Cretaceous Terrestrial Ecosystems (Lucas, S.G.; Kirkland J.I. \& Estep, J.W., eds.). New Mexico Museum of Natural History and Science Bulletin, 14: 29-38.

Bordet, P. (1977). Albert F. de Lapparent (1905-1075). Notice biographique. Mémoire hors-série de la Société géologique de France, 8: 7-18.

Brill, K. \& Carpenter, K. (2007). A description of a new ornithopod from the Lytle member of th Purgatoire Formation (Lower Cretaceous) and a reassessment of the skull of Camptosaurus. In: Horns and beaks. Ceratopsian and ornithopod dinosaurs (Carpenter, K., ed.). Indiana University Press, Bloomington and Indianapolis, 49-67.

Buffetaut, E. (1991). On the age of the Cretaceous dinosaur-bearing beds of southern Laos. Newsletters on Stratigraphy, 24: 59-73.

Buffetaut, E. \& Suteethorn, V. (1998a). The biogeographic significance of the Mesozoic vertebrates from Thailand. In: Biogeography and geological evolution of SE Asia (Hall, R. \& Holloway, J.D., eds.), Backhuys Publishers, Leiden, 83-90.

Buffetaut, E. \& Suteethorn, V. (1998b). Early Cretaceous dinosaurs from Thailand and their bearing on the early evolution and biogeographical history of some groups of Cretaceous dinosaurs. In: Lower and Middle Cretaceous Terrestrial Ecosystems (Lucas, S.G.; Kirkland J.I. \& Estep, J.W., eds.). New Mexico Museum of Natural History and Science Bulletin, 14: 205-210.

Buffetaut, E. \& Suteethorn, V. (1998c). Iguanodontid dinosaurs form the Lower Cretaceous of Thailand. Journal of Vertebrate Paleontology,18(supplement to number 3): 30A.

Buscalioni, A.D. \& Sanz, J.L. (1984). Los arcosaurios (Reptilia) del Jurásico Superior-Cretácico Inferior de Galve (Teruel, España). Teruel, 71: 9-30.

Butler, R.J. (2008). Book review: Horns and beaks: Ceratopsian and ornithopod dinosaurs. Journal of Vertebrate Paleontology, 28: 582-583. doi:10.1671/ 02724634(2008)28[582:HABCAO]2.0.CO;2 
Calvo, J.O.; Porfiri, J.D. \& Novas, F.E. (2007). Discovery of a new ornithopod dinosaur from the Portezuelo Formation (Upper Cretaceous), Neuquén, Patagonia, Argentina. Arquivos do Museu Nacional, Rio de Janeiro, 65: 471-483.

Carpenter, K. \& Ishida, Y. (2010). Early and "Middle" Cretaceous iguanodonts in time and space. Journal of Iberian Geology, 36: 145-164.

Carpenter, K. \& Wilson, Y. (2008). A new species of Camptosaurus (Ornithopoda: Dinosauria) from the Morrison Formation (Upper Jurassic) of dinosaur National Monument, Utah and a biomechanical analysis of its forelimb. Annals of Carnegie Museum, 76: 227-263. doi:10.2992/0097-4463(2008)76[227:ANSO$\mathrm{CO} 2.0 . \mathrm{CO} ; 2$

Carpenter, K.; DiCroce, T.; Gilpin, D.; Kinneer, B.; Sanders, F.; Tidwell, V. \& Shaw, A. (2002). Origins of the Early and «Middle» Cretaceous dinosaurs of North America: Implications for plate tectonics. In: Proceedings of the International Symposium on New Concepts in Global Tectonics, held in May 2002 in La Junta, Colorado, (Maslov, L., ed.). Otero Junior College Press, La Junta, 289-308.

Chabli, S. (1988). Étude anatomique et systématique de Gravisaurus tenerensis n. g. n. sp. (Dinosaurien, Ornithischien) du gisement de Gadoufaoua (Aptien du Niger). $\mathrm{PhD}$ Thesis, Université de Paris VII, París, 164 pp..

Company Rodríguez, J. (2004). Vertebrados continentales del Cretácico superior (Campaniense-Maastrichtiense) de Valencia. Tesis Doctoral. Universitat de Vàlencia, Valencia, 410 pp. (inédita, defendida en 2005).

Contreras-Izquierdo, R.; Cruzado-Caballero, P.; TorcidaFernández Baldor, F.; Huerta, P. Izquierdo Montero, L.A.; Montero Huerta, D.; Pérez Martínez, G. \& Urién Montero, V. (2009). Un ilion de un dinosaurio «iguanodóntido» procedente del Cretácico Inferior de Burgos (España). In: Actas de las IV Jornadas Internacionales sobre Paleontología de Dinosaurios y su Entorno (Huerta Hurtado, P. \& Torcida-Fernández Baldor, F., eds). Salas de los Infantes, Burgos, 187-195.

DiCroce, T. \& Carpenter, K. (2001). New ornithopod from the Cedar Mountain Formation (Lower Cretaceous) of Eastern Utah. In: Mesozoic Vertebrate Life (Tanke, D.H. \& Carpenter, K., eds.). Indiana University Press, Bloomington e Indianapolis, 183-196.

Dong Z. (2002). A new armored dinosaur (Ankylosauria) from Beipiao Basin, Liaoning Province, Northeastern China. Vertebrata Palasiatica, 40: 276-285.

Fernández-Galiano, D. (1958). Descubrimientos de restos de Dinosaurios en Galve. Teruel, 20: 1-3.

Fernández-Galiano, D. (1960). Yacimientos de Dinosaurios en Galve. Teruel. Boletin de la Real Sociedad Española de Historia Natural (Seccion Geologica), 58: 95-96.

Forster, C.A. (1990). The postcranial skeleton of the ornithopod dinosaur Tenontosaurus tilletti. Journal of Vertebrate Paleontology, 10: 273-294. doi:10.1080/ 02724634.1990.10011815

Fuentes Vidarte, C.; Meijide Calvo, M.; Meijide Fuentes, F. \& Meijide Fuentes, M. (2005). Fauna de vertebrados del Cretácico Inferior del yacimiento de «Zorralbo» en
Golmayo (Soria, España). Revista Española de Paleontología, número extraordinario 10: 83-92.

Galton, P.M. (1976). The dinosaur Vectisaurus valdensis (Ornitischia: Iguanodontidae) from the lower Cretaceous of England. Journal of Paleontology, 50: 976-984.

Galton, P.M. (2009). Notes on Neocomian (Lower Cretaceous) ornithopod dinosaurs from England - Hypsilophodon, Valdosaurus, «Camptosaurus», «Iguanodon»and referred specimens from Romania and elsewhere. Revue de Paléobiologie, 28: 211-273.

Galton, P.M. \& Jensen, J.A. (1979). Remains of ornithopod dinosaurs from the Lower Cretaceous of North America. Brigham Young University Geology Studies, 25: 1-10.

Gasulla, J.M.; Sanz, J.L.; Ortega, F. \& Escaso, F. (2009). Iguanodon bernissartensis from the Early Aptian of Morella (Castellón, Spain). In: Tribute to Charles Darwin and Bernissart iguanodons: New perspectives on Vertebrate Evolution and Early Cretaceous Ecosytems. Brussels 2009. Programme, Abstracts and Field Trips Guidebook (Godefroit, P. \& Lambert, O., eds.), 44.

Gilmore, C.W. (1909). Osteology of the Jurassic reptile Camptosaurus, with a revision of the species of the genus, and descriptions of two new species. Proceedings of the United States National Museum, 36: 197-332.

Gilpin, D.; Carpenter, K. \& Dicroce, K. (2002). New ornithopod with hadrosaur-like features from the Lower Cretaceous of Utah. Journal of Vertebrate Paleontology, 22 (supplement to number 3): 58A-59A.

Gilpin, D.; DiCroce, T. \& Carpenter, K. (2007). A possible new basal hadrosaur from the Lower Cretaceous Cedar Mountain Formation of eastern Utah. In: Horns and beaks. Ceratopsian and ornithopod dinosaurs (Carpenter, K., ed.). Indiana University Press, Bloomington and Indianapolis, 79-89 (publicado en octubre de 2006).

Glut, D.F. (1997). Dinosaurs. The Encyclopedia. McFarland Press, Jefferson, xi + 1076 pp.

Godefroit, P. (2009). 130 years ago: the discovery of the Bernissart iguanodons. In: Tribute to Charles Darwin and Bernissart Iguanodons: New perspectives on Vertebrate Evolution and Early Cretaceous Ecosytems. Brussels 2009. Programme, Abstracts and Field Trips Guidebook (Godefroit, P. \& Lambert, O., eds.), 129-135.

Godefroit, P. \& Lambert, O. (2007). A re-appraisal of Craspedodon lonzeensis Dollo, 1883 from the Upper Cretaceous of Belgium: the first record of a neoceratopsian dinosaur in Europe?. Bulletin de l'Institut Royal des Sciences Naturelles de Belgique, Sciences de la Terre, 77: 83-93.

Godefroit, P.; Dong Z, Bultynck, P.; Li H. \& Feng, L. (1998). New Bactrosaurus (Dinosauria, Hadrosauroidea) material from Iren Dabasu (Inner Mongolia, P.R. China). Bulletin de l'Institut Royal des Sciences Naturelles de Belgique. Sciences de la Terre, 68 (Supplement): 3-70.

Godefroit, P.; Li H. \& Shang C. (2005). A new primitive hadrosauroid dinosaur from the Early Cretaceous of Inner Mongolia (P.R. China). Comptes Rendus Palevol, 4(8), 697-705. doi:10.1016/j.crpv.2005.07.004

Godefroit, P.; Codrea, V. \& Weishampel, D.B. (2009). Osteology of Zalmoxes shqiperorum (Dinosauria, Ornithopoda), based on new specimens from the Upper 
Cretaceous of Nalat-Vad (Romania). Geodiversitas, 31: 525-553. doi:10.5252/g2009n3a3

Head, J.J. (1998). A new species of basal hadrosaurid (Dinosauria, Ornithischia) from the Cenomanian of Texas. Journal of Vertebrate Paleontology, 18: 718738. doi:10.1080/02724634.1998.10011101

Head, J.J. (2001). A reanalysis of the phylogenetic position of Eolambia caroljonesa (Dinosauria, Iguanodontia). Journal of Vertebrate Paleontology, 21: 392-396. doi:10.1671/0272-4634(2001)021[0392:AROTPP] 2.0.CO;2

Head, J.J. \& Kobayashi, Y. (2001). Biogeographic histories and chronologies of derived iguanodontians. In: VII International symposium on Mesozoic Terrestrial Ecosystems, Buenos Aires, September 26-October 1, 1999 (Ed. H.A. Leanza). Asociación Paleontológica Argentina. Publicación Especial, 7, 107-111.

Hoffet, J.H. (1944a). Description des ossements les plus caractéristiques appartenant à des Avipelviens du Sénonien du Bas-Laos. Bulletin du Conseil des Recherches Scientifique de l'Indochine, 1944: 179-186.

Hoffet, J.H. (1944b). L' âge des formations à Dinosaures du Bas-Laos. Bulletin du Conseil des Recherches Scientifique de l'Indochine, 1944: 187-191.

Horner, J.R.; Weishampel, D.B. \& Forster, C.A. (2004). Hadrosauridae. In: The Dinosauria, Second Edition (Weishampel, D.B.; Dodson, P. \& Osmólska, H., eds.). University of California Press, Berkeley, Los Ángeles - Londres, 438-463.

Hulke. J.W. (1879). Vectisaurus valdensis, a new Wealden dinosaur. Quarterly Journal of the Geological Society, 35: 421-424.

Itterbeeck, J. van, Markerich, V.S. \& Horne, D.J. (2004). The age of the dinosaur-bearing Cretaceous sediments at Dashuiguo, Inner Mongolia, P.R. China based on charophytes, ostracods and palynomorphs. Cretaceous Research, 25: 391-409. doi:10.1016/j.cretres.2004.02.001

Kirkland, J.I. (1998). A new hadrosaurid from the Upper Cedar Mountain Formation (Albian-Cenomanian: Cretaceous) of Eastern Utah- The oldest known hadrosaurid (Lambeosaurine?). In: Lower and Middle Cretaceous Terrestrial Ecosystems (Lucas, S.G.; Kirkland J.I. \& Estep, J.W., eds.). New Mexico Museum of Natural History and Science Bulletin, 14: 283-295.

Knoll, F. (2009). A large iguanodont from the Upper Barremian of the Paris Basin. Geobios, 42: 755-764. doi:10.1016/j.geobios.2009.06.002

Kobayashi, Y. \& Azuma, Y. (2003). A new iguanodontian (Dinosauria: Ornithopoda) from the Lower Cretaceous Kitadani Formation of Fukui Prefecture, Japan. Journal of Vertebrate Paleontology, 23: 166-175. doi:10.1671/0272-4634(2003)23[166:ANIDOF] 2.0.CO;2

Lapparent, A.F. de. (1960). Los dos dinosaurios de Galve. Teruel, 24: 177-197.

Lu, J. (1997). A new Iguanodontidae (Probactrosaurus mazongshanensis sp. nov.) from Mazongshan Area, Gansu Province, China. In: Sino-Japanese Silk Road Dinosaur Expedition (Dong Z., ed). China Ocean Press, Pekín, 27-47.
Lydekker, R. (1888). Note on a new Wealden iguanodont and other dinosaurs. Quarterly Journal of the Geological Society of London, 44: 46-61. doi:10.1144/ GSL.JGS.1888.044.01-04.08

Lydekker, R. (1889). Notes on new and other Dinosaurian remains. Geological Magazine (series 3), 6: 352-357.

Lydekker, R. (1890). Contributions to our knowledge of the dinosaurs of the Wealden, and the Sauropterygia of the Purbeck and Oxford clay. Quarterly Journal of the Geological Society of London, 46: 36-53. doi:10.1144/GSL.JGS.1890.046.01-04.05

Maisch, M.W. (1997). The Lower Cretaceous dinosaur Iguanodon cf. fittoni LYDEKKER, 1889 (Ornithischia) from Salas de los Infantes (Province Burgos, Spain). Neues Jahrbuch für Geologie und Paläontologie Monatshefte 1997: 232-241.

Maxwell, W.D. \& Cifelli, R. (2002). Reanalysis of the ornithischian dinosaur Eolambia. Journal of Vertebrate Paleontology, 22 (supplement to number 3): 85A.

McDonald, A.T. (2011). The taxonomy of species assigned to Camptosaurus (Dinosauria: Ornithopoda). Zootaxa, 2783: 52-68.

McDonald, A.T.; Barrett, P.M. \& Chapman, S.D. (2010). A new basal iguanodont (Dinosauria: Ornithischia) from the Wealden (Lower Cretaceous) of England. Zootaxa, 2569: 1-43.

Molnar, R.E. (1996). Observations on the australian ornithopod dinosaur, Muttaburrasaurus. In: Proceedings of the Gondwanan Dinosaur Symposium (Novas, F.E. \& Molnar, R.E., eds.). Memoirs of the Queensland Museum, 39(3), 639-652.

Mongin, D. (1966). Description paleontologique de quelques lamellibranches limniques des facies wealdiens. Notas y Comunicaciones del Instituto Geológico y Minero de España, 91: 41-60.

Norman, D.B. (1980). On the ornithischian dinosaur Iguanodon bernissartensis from the Lower Cretaceous of Bernissart (Belgium). Mémoires de l' Institut Royal des Sciences Naturelles de Belgique, 178: 1-105.

Norman, D.B. (1986). On the anatomy of Iguanodon atherfieldensis (Ornithischia: Ornithopoda). Bulletin de l'Institute Royale des Sciences Naturelles de Belgique, Sciences de la Terre, 56: 281-372.

Norman, D.B. (1987). Wealden dinosaur biostratigraphy. In: Fouth Symposium on Mesozoic terrestrial ecosystems, Short Papers (Currie, P.J. \& Koster, E.H., eds). Tyrrell Museum of Palaentology (Occasional Papers of the Royal Tyrrell Museum of Palaentology, 3), Drumheller, 165-170.

Norman, D.B. (1990). A review of Vectisaurus valdensis, with comments on the family Iguanodontidae. In: Dinosaur systematics. Approaches and Perspectives (Carpenter, K. \& Currie, P.J., eds.). Cambridge University Press, Cambridge, 147-162. doi:10.1017/ CBO9780511608377.014

Norman, D.B. (1996). On Mongolian ornithopods (Dinosauria: Ornithischia). 1. Iguanodon orientalis Rozhdestwensky 1952. Zoological Journal of the Linnean Society, 116: 303-315. doi:10.1111/j.1096-3642.1996. tb00125.x 
Norman, D.B. (1998). On Asian ornithopods (Dinosauria: Ornithischia). 3. A new species of iguanodontid dinosaur. In: A study of fossil vertebrates (Norman, D.B.; Milner, A.R. \& Milner A.C., eds.). Zoological Journal of the Linnean Society, 122: 291-348.

Norman, D.B. (2002). On Asian ornithopods (Dinosauria: Ornithischia). 4. Probactrosaurus Rozhdestvensky, 1966. In: Archosaurian anatomy and palaeontology. Essais in memory of Alick D. Walker (Norman, D.B. \& Gower, D.J. Eds.). Zoological Journal of the Linnean Society, 136: 133-149.

Norman, D.B. (2004). Basal Iguanodontia. In: The Dinosauria, Second Edition (Weishampel, D.B.; Dodson, P. \& Osmólska, H., eds.). University of California Press, Berkeley, Los Ángeles - Londres, 413-437.

Norman, D.B. (2010). A taxonomy of iguanodontians (Dinosauria: Ornithopoda) from the lower Wealden Group (Cretaceous: Valanginian) of southern England. Zootaxa, 2489: 47-66.

Norman, D.B. \& Sues, H.D. (2000). Ornithopods from Kazakhstan, Mongolia and Siberia. In: The Age of Dinosaurs in Russia and Mongolia (Benton, M.J.; Shishkin, M.A.; Unwin, D.M. \& Kurochkin, E.N., eds.). Cambridge University Press, Cambridge, 462-479.

Norman, D.B. \& Weishampel, D.B. (1990). Iguanodontidae and related Ornithopoda. In: The Dinosauria (Weishampel, D.B.; Dodson, P. \& Osmólska, H., eds.). University of California Press, Berkeley, 510- 533.

Ostrom, J.H. (1970). Stratigraphy and paleontology of the Cloverly Formation (Lower Cretaceous) of the Bighorn Basin Area, Wyoming and Montana. Bulletin of the Peabody Museum of Natural History, Yale University, 35: 1-234.

Paul, G.S. (2007). Turning the old into the new: a separate genus for the gracile iguanodont from the wealden of England. In: Horns and beaks. Ceratopsian and ornithopod dinosaurs (Carpenter, K., ed.). Indiana University Press, Bloomington and Indianapolis, 69-77 (publicado en octubre de 2006).

Paul, G.S. (2008). A revised taxonomy of the iguanodont dinosaur genera and species. Cretaceous Research, 29: 192-216.

Rothschild, B.M. (1997). Dinosaurian paleopathology. In: The Complete Dinosaur (Farlow, J.O. \& Brett-Surman, M.K., eds.). Indiana University Press, Bloomington e Indianapolis, 426-448.

Rothschild, B.M. \& Berman, D. (1991). Fusion of caudal vertebrae in Late Jurassic sauropods. Journal of Vertebrate Paleontology, 11: 29-36. doi:10.1080/02724634. 1991.10011373

Royo-Torres, R. \& Cobos, A. (2007). En ruta con los dinosaurios de Teruel. In: Teruel: territorio paleontológico (Alcalá, L. \& Cobos, A., eds.). Fundación Conjunto Paleontológico de Teruel-Dinópolis (Fundamental, 11), 65-76.

Rozhdestvensky, A.K. (1967). New iguanodonts from Central Asia. International Geology Review, 9: 556566. doi:10.1080/00206816709474485

Ruiz-Omeñaca, J.I. (2006). Restos directos de dinosaurios (Saurischia, Ornithischia) en el Barremiense
(Cretácico Inferior) de la Cordillera Ibérica en Aragón (Teruel, España). Tesis doctoral, Universidad de Zaragoza, Zaragoza, xii + 439 pp. (inédita). [disponible en: http://www.aragosaurus.com/secciones/publicaciones/artic/ruizomenaca2006.pdf]

Ruiz-Omeñaca, J.I. \& Canudo, J.I. (2003). Dinosaurios (Saurischia, Ornithischia) en el Barremiense (Cretácico Inferior) de la Península Ibérica. In: Dinosaurios y otros Reptiles Mesozoicos en España (Pérez-Lorente, F., coord.). Instituto de Estudios Riojanos (IER, Ciencias de la Tierra, 26), Logroño, 269-312. (publicado en 2004).

Ruiz-Omeñaca, J.I. \& Canudo, J.I. (2004). Dinosaurios ornitópodos del Cretácico inferior de la Península Ibérica. In: VI Congreso Geológico de España, Zaragoza, 12 al 15 de julio, 2004 (Liesa Carrera, C.; Pocovi Juan, A.; Sancho Marcén, C.; Colombo Piñol, F.; González Rodríguez, A. \& Soria de Miguel, A.R., eds.). GeoTemas, 6: 63-65.

Ruiz-Omeñaca, J.I.; Canudo, J.I. \& Cuenca-Bescós, G. (1998). Sobre las especies de Iguanodon (Dinosauria, Ornithischia) encontradas en el Cretácico Inferior de España. Geogaceta, 24: 275-277.

Ruiz-Omeñaca, J.I.; Canudo, J.I.; Aurell, M.; Barco, J.L. \& Royo-Torres, R. (2003). El «iguanodóntido» de La Maca (Galve, Teruel): historia y sistemática. In: Libro de Resúmenes de las XIX Jornadas de Paleontología, Morella 2003 (Pardo Alonso, M.V. \& Gozalo, R., eds.), 148-149.

Ruiz-Omeñaca, J.I.; Canudo, J.I.; Aurell, M.; Bádenas, B.; Barco, J.L.; Cuenca-Bescós, G. \& Ipas, J. (2004a). Estado de las investigaciones sobre los vertebrados del Jurásico Superior y Cretácico Inferior de Galve (Teruel). Estudios Geológicos, 60(3-6): 179-202 (publicado en 2005).

Ruiz-Omeñaca, J.I.; Canudo, J.I. \& Barco, J.L. (2004b). Two new ornithopod dinosaurs from the Lower Cretaceous (Lower Barremian, Camarillas Formation) of Galve (Teruel, Spain). In: 2nd EAVP Meeting. July 1924, 2004. Brno, Czech Republic. Abstracts of papers and posters with program, Excursion Guidebook (Dostal, O.; Gregorova, R. \& Ivanov, M., eds.), 41.

Ruiz-Omeñaca, J.I.; Canudo, J.I. \& Cuenca-Bescós, G. (2004c). Ornithopod dinosaurs from the Early Cretaceous of the Iberian Peninsula (Spain and Portugal). Journal of Vertebrate Paleontology, 24(supplement to number 3): 107A.

Ruiz-Omeñaca, J.I.; Canudo, J.I. \& Infante, P. (2005). Presencia de un posible alosáurido (Dinosauria: Theropoda) en el Cretácico Inferior (Barremiense inferior) de La Maca 3 (Galve, Teruel). In: XXI Jornadas de la Sociedad Española de Paleontología, Sevilla, 4 a 8 de octubre de 2005 (Dirección General de Bienes Culturales, Bernáldez Sanchez, E.; Mayoral Alfaro E. \& Guerrero dos Santos A., eds.). Consejería de Cultura de la Junta de Andalucía, Sevilla, 117-118.

Ruiz-Omeñaca, J.I.; Pereda Suberbiola, X.; Torcida Fernández-Baldor, F.; Maisch, M.; Izquierdo, L.A.; Huerta, P.; Contreras, R.; Montero Huerta, D.; Pérez Martínez, G.; Urién Montero, V. \& Welle, J. (2009). Resto mandibular de ornitópodo iguanodontoideo (Dinosau- 
ria) del Cretácico Inferior de Salas de los Infantes (Burgos) en las colecciones del Institut für Geowissenschaften de Tubinga (Alemania). Geogaceta, 45: 63-66.

Sanz, J.L.; Casanovas, M.L. \& Santafé, J.V. (1982). Paleontología. In: Geología y Paleontología (Dinosaurios) de las Capas Rojas de Morella (Castellón, España). Diputación Provincial de Castellón y Diputació de Barcelona, Castellón y Barcelona, 69-169.

Sanz, J.L.; Casanovas, M.L. \& Santafé, J.V. (1984). Iguanodóntidos (Reptilia, Ornithopoda) del yacimiento del Cretácico inferior de San Cristóbal (Galve, Teruel). Acta Geológica Hispánica, 19: 171-176.

Sanz, J.L.; Buscalioni, A.; Casanovas, M.L. \& Santafé, J.V. (1987). Dinosaurios del Cretácico inferior de Galve (Teruel, España). In: Geología y paleontologia (arcosaurios) de los yacimientos cretácicos de Galve (Teruel) y Tremp (Lérida) (Sanz, J.L., coord.). Estudios Geológicos, Volumen extraordinario Galve-Tremp: 45-64.

Sanz, J.L.; Buscalioni, A.D.; Moratalla, J.J.; Francés, V. \& Antón, M. (1990). Los reptiles mesozoicos del registro español. Consejo Superior de Investigaciones Científicas (Monografías del Museo Nacional de Ciencias Naturales, 2), Madrid, 81 pp.

Scheetz, R.; Britt, B. \& Higgerson, J. (2010). A large, tall-spined iguanodontid dinosaur from the Early Cretaceous (early Albian) basal Cedar Mountain Formation of Utah. Journal of Vertebrate Paleontology, 30(supplement to number 3): 158A.

Sereno, P.C. (1986). Phylogeny of the bird-hipped dinosaurs (Order Ornithischia). National Geographic Research, 2: 234-256.

Sereno, P.C. (1997). The origin and evolution of dinosaurs. Annual review of Earth and Planetary Sciences, 25: 435-489. doi:10.1146/annurev.earth.25.1.435

Sereno, P.C. (1998). A rationale for phylogenetic definitions, with application to the higher-level taxonomy of Dinosauria. Neues Jahrbuch für Geologie und Paläontologie, Abhandlungen, 210: 41-83.

Sereno, P.C. (1999a). The evolution of dinosaurs. Science, 284: 2137-2147. doi:10.1126/science.284.5423.2137

Sereno, P.C. (1999b). A rationale for dinosaurian taxonomy. Journal of Vertebrate Paleontology, 19: 788790. doi:10.1080/02724634.1999.10011192

Sereno, P.C. (2005). Stem Archosauria [version 1.0, 7 de noviembre de 2005]. TaxonSearch. [http://www.taxonsearch.org/Archive/stem-archosauria-1.0.php].

Sues, H.D. (1997). Hypsilophodontidae. In: Encyclopedia of Dinosaurs (Currie, P.J. \& Padian, K., eds.). Academic Press, San Diego, 356-358.

Tang F.; Luo Z, Zhou Z, You H.; Georgi, J.A.; Tang Z. \& Wang X. (2001). Biostratigraphy and palaeoenvironment of the dinosaur-bearing sediments in Lower Cretaceous of Mazongshan area, Gansu Province, China. Cretaceous Research, 22: 115-129. doi:10.1006/ cres. 2000.0242

Tanke, D.H. \& Rothschild, B.M. (1997). Paleopathology. In: Encyclopedia of Dinosaurs (Currie, P.J. \& Padian K., eds.). Academic Press, San Diego, 525-530.

Tanke, D.H. \& Rothschild, B.M. (2002). Dinosores: An annotated bibliography of dinosaur paleopathology and related topics. 1838-2001. New Mexico Museum of Natural History and Science Bulletin, 20: 1-96.

Taquet, P. (1976). Géologie et Paléontologie du gisement de Gadoufaoua (Aptian du Niger). Centre National de la Recherche Scientifique (Cahiers de Paleontologie), París, 191 pp.

Taquet, P. \& Russell, D.A. (1999). A massively-constructed iguanodont from Gadoufaoua, Lower Cretaceous of Niger. Annales de Paléontologie, 85: 85-96. doi:10.1016/S07533969(99)80009-3

Taquet, P.; Battail, B. \& Dejax, J. (1992). New discoveries of sauropod and ornithopod dinosaurs in the Lower Cretaceous of Laos. Journal of Vertebrate Paleontology, 12 (supplement to number 3): 55A.

Torcida Fernández-Baldor, F.; Izquierdo Montero, L.A.; Contreras Izquierdo, R.; Huerta, P.; Montero Huerta, D.; Pérez Martínez, G. \& Urén Montero, V. (2006). Un dinosaurio «iguanodóntido» del Cretácico Inferior de Burgos (España). In: Actas de las III Jornadas Internacionales sobre Paleontología de Dinosaurios y su Entorno (Colectivo Arqueológico y Paleontológico de Salas, ed.). Salas de los Infantes, Burgos, 349-363.

Torcida Fernández-Baldor, F.; Ruiz-Omeñaca, J.I.; Pereda Suberbiola, X.; Maisch, M.W.; Izquierdo, L.A.; Huerta, P.; Contreras, R.; Montero Huerta, D.; Pérez Martínez, G.; Urién Montero, V. \& Welle, J. (2008). La colección de restos de dinosaurios del Cretácico Inferior de Salas de los Infantes (Burgos, España) depositada en el Institut und Museum für Geologie und Paläontologie de Tübingen (Alemania). In: Libro de resúmenes. XXIV Jornadas de la Sociedad Española de Paleontología. Museo del Jurásico de Asturias (MUJA), Colunga, 15-18 de Octubre del 2008 (RuizOmeñaca, J.I.; Piñuela L. \& García-Ramos, J.C., eds.), 205-206.

Wang X. \& Xu X. (2001). A new iguanodontid (Jinzhousaurus yangi gen. et sp. nov.) from the Yixian Formation of western Liaoning, China. Chinese Science Bulletin, 46: 1669-1672. doi:10.1007/BF02900633

Weishampel, D.B. (1990). Dinosaurian distribution. In: The Dinosauria (Weishampel, D.B.; Dodson, P. \& Osmólska, H., eds.). University of California Press, Berkeley, 63-139.

Weishampel, D.B. \& Bjork, P.R. (1989). The first indisputable remains of Iguanodon (Ornithischia: Ornithopoda) from North America: Iguanodon lakotaensis, sp. nov. Journal of Vertebrate Paleontology, 9: 56-66. doi:10.1080/02724634.1989.10011738

Weishampel, D.B. \& Heinrich, R.E. (1992). Systematics of Hypsilophodontidae and basal Iguanodontia (Dinosauria: Ornithopoda). Historical Biology, 6: 159-184. doi:10.1080/10292389209380426

Weishampel, D.B. \& Horner, J.R. (1990). Hadrosauridae. In: The Dinosauria (Weishampel, D.B.; Dodson, P. \& Osmólska, H., eds.). University of California Press, Berkeley, 534-563.

Weishampel, D.B.; Norman, D.B. \& Grigorescu, D. (1993). Telmatosaurus transsylvanicus from the Late Cretaceous of Romania: The most basal hadrosaurid dinosaur. Palaeontology, 36: 361-385. 
Weishampel, D.B.; Jianu, C.M.; Csiki, Z. \& Norman, D.B. (2003). Osteology and phylogeny of Zalmoxes (n. g.), an unusual euornithopod dinosaur from the latest Cretaceous of Romania. Journal of Systematic Palaeontology, 1: 85-123. doi:10.1017/S1477201903001032

Weishampel, D.B.; Barrett, P.M.; Coria, R.; Le Loeuff, J.; Xu X.; Zhao X.; Shani, A.; Gomani, E.M.P. \& Noto, C.R. (2004). Dinosaur distribution. In: The Dinosauria, Second Edition (Weishampel, D.B.; Dodson, P. \& Osmólska, H., eds.). University of California Press, Berkeley, Los Ángeles - Londres, 517-606.

Xu X.; Zhao X.; Lü J.; Huang W.; Li Z. \& Dong Z. (2000). A new iguanodontian from Sangping Formation of Neixiang, Henan and its stratigraphical implications. Vertebrata PalAsiatica, 38: 176-191.

Yans, J.; Dejax, J.; Pons, D.; Dupuis, C. \& Taquet, P. (2005). Implications paléontologiques et géodynamiques de la datation palynologique des sédiments à faciès wealdien de Bernissart (bassin de Mons, Belgique). Comptes Rendus Palevol, 4: 135-150. doi: 10.1016/j.crpv.2004.12.003

You H. (2002). Mazongshan dinosaur assemblage from late Early Cretaceous of northwest China. Tesis docto- ral, University of Pennsylvania, Philadelphia, $x+164$ pp. (inédita).

You H.; Ji Q.; Li J. \& Li Y. (2003a). A new hadrosauroid dinosaur from the mid-Cretaceous of Liaoning Province, P. R. China. Acta Geologica Sinica-English edition, 77: 148-154.

You H.; Luo Z.; Shubin, N.H.; Witmer, L.M.; Tang Z. \& Tang F. (2003b). The earliest-known duck-billed dinosaur from deposits of late Early Cretaceous age in northwest China and hadrosaur evolution. Cretaceous Research, 24: 347-355. doi:10.1016/S0195-6671(03)00048-X

You H.; Ji Q. \& Li D. (2005) Lanzhousaurus magnidens gen. et sp. nov. from Gansu Province, China: the largest-toothed herbivorous dinosaur in the world. Geological Bulletin of China, 24: 785-794.

You, H. \& Li, D. (2009). A new basal hadrosauriform dinosaur (Ornithischia: Iguanodontia) from the Early Cretaceous of northwestern China. Canadian Journal of Earth Sciences, 46: 949-957. doi:10.1139/E09-067

Recibido el 8 de abril de 2010 Aceptado el 4 de noviembre de 2010 Publicado online el 6 de mayo de 2011

\section{Apéndices}

Apéndice 1.-Delapparentia turolensis nov. gen. et sp. de La Maca 3, Galve (Teruel, Barremiense inferior). Listado de materiales del Museo de Teruel. Todas las piezas están sigladas como I.G. («Iguanodon Galve») seguidas de un número, y tienen además una «sigla de campo», posiblemente puesta por Lapparent.

\begin{tabular}{|c|c|c|c|c|}
\hline $\begin{array}{l}\text { Sigla del } \\
\text { Museo de Teruel }\end{array}$ & $\begin{array}{l}\text { Sigla de } \\
\text { Lapparent (1960) }\end{array}$ & $\begin{array}{l}\text { Material según } \\
\text { el Museo de Teruel }\end{array}$ & $\begin{array}{l}\text { Material según } \\
\text { Lapparent (1960) }\end{array}$ & Observaciones \\
\hline $\begin{array}{l}\text { I.G. } 446 \\
\text { I.G.447 } \\
\text { I.G.448 } \\
\text { I.G.449 }\end{array}$ & $\begin{array}{l}V^{1} \\
V^{2} \\
V^{3} \\
V^{4}\end{array}$ & $\begin{array}{l}\text { vértebra cervical } \\
\text { vértebra cervical } \\
\text { vértebra cervical } \\
\text { vértebra cervical }\end{array}$ & 4 vértebras cervicales & \\
\hline I.G.450 & $\mathrm{V}^{5}$ & vértebra sacral & 2 vértebras sacras & \\
\hline $\begin{array}{l}\text { I.G. } 450 \text { bis } \\
\text { I.G. } 451 \\
\text { I.G. } 452 \\
\text { I.G. } 453 \\
\text { I.G.454 } \\
\text { I.G. } 455 \\
\text { I.G.456 } \\
\text { I.G. } 457 \\
\text { I.G. } 458 \\
\text { I.G. } 459 \\
\text { I.G.460 } \\
\text { I.G.461 } \\
\text { I.G.462 } \\
\text { I.G.463 }\end{array}$ & $\begin{array}{l}V^{5} b i s \\
V^{6} \\
V^{7} \\
V^{8} \\
V^{9} \\
V^{10} \\
V^{11} \\
V^{12} \\
V^{13} \\
V^{14} \\
V^{15} \\
V^{16} \\
V^{17} \\
V^{18}\end{array}$ & $\begin{array}{l}\text { vértebra caudal } \\
\text { vértebra caudal } \\
\text { vértebra caudal } \\
\text { vértebra caudal } \\
\text { vértebra caudal } \\
\text { vértebra caudal } \\
\text { vértebra caudal } \\
\text { vértebra caudal } \\
\text { vértebra caudal } \\
\text { NO FIGURA } \\
\text { NO FIGURA } \\
\text { vértebra } \\
\text { vértebra caudal } \\
\text { vértebra caudal }\end{array}$ & 14 vértebras caudales & $\begin{array}{l}\text { desaparecida } \\
\text { encaja con } \mathrm{V}^{27} \mathrm{y} \mathrm{V}^{44} \\
\text { encaja con } \mathrm{V}^{47} \\
\text { pertenece a Aragosaurus } \\
\text { encaja con } \mathrm{V}^{54} \\
\text { encaja con } \mathrm{V}^{48} \mathrm{y} \mathrm{V}^{53} \\
\text { encaja con } \mathrm{V}^{46} \\
\text { encaja con } \mathrm{V}^{45} \\
\text { es vértebra dorsal } \\
\text { encaja con } \mathrm{V}^{49} \mathrm{y} \mathrm{V}^{52} \\
\text { ¿ vértebra cervical? } \\
\text { ¿Aragosaurus? }\end{array}$ \\
\hline $\begin{array}{l}\text { I.G.464 } \\
\text { I.G.465 } \\
\text { I.G.466 } \\
\text { I.G.467 }\end{array}$ & $\begin{array}{l}\mathrm{V}^{19} \\
\mathrm{~V}^{20} \\
\mathrm{~V}^{21} \\
\mathrm{~V}^{22} \\
\mathrm{~V}^{22} \text { 'bis }\end{array}$ & $\begin{array}{l}\text { arco hemal } \\
\text { arco hemal } \\
\text { arco hemal } \\
\text { arco hemal } \\
\text { arco hemal }\end{array}$ & 5 arcos hemales & \\
\hline
\end{tabular}


Apéndice 1 (continuación).-Delapparentia turolensis nov. gen. et sp. de La Maca 3, Galve (Teruel, Barremiense inferior). Listado de materiales del Museo de Teruel. Todas las piezas están sigladas como I.G. («Iguanodon Galve») seguidas de un número, y tienen además una «sigla de campo», posiblemente puesta por Lapparent.

\begin{tabular}{|c|c|c|c|c|}
\hline $\begin{array}{l}\text { Sigla del } \\
\text { Museo de Teruel }\end{array}$ & $\begin{array}{l}\text { Sigla de } \\
\text { Lapparent (1960) }\end{array}$ & $\begin{array}{l}\text { Material según } \\
\text { el Museo de Teruel }\end{array}$ & $\begin{array}{l}\text { Material según } \\
\text { Lapparent (1960) }\end{array}$ & Observaciones \\
\hline I.G.468 & $\begin{array}{l}V^{23} \\
V^{24} \\
V^{25} \\
V^{26} \\
V^{27} \\
V^{28} \\
V^{29} \\
V^{30} \\
V^{31} \\
V^{32} \\
V^{33} \\
V^{34} \\
\\
V^{35} \\
V^{36} \\
V^{37} \\
V^{38} \\
V^{39} \\
V^{40} \\
V^{41} \\
V^{42} \\
V^{43} \\
V^{44} \\
V^{45} \\
V^{46} \\
V^{47} \\
V^{48} \\
V^{49} \\
V^{50} \\
V^{51} \\
V^{52} \\
V^{53} \\
V^{54} \\
V^{55}\end{array}$ & neurapófisis (36 piezas) & 28 neurapófisis & $\begin{array}{l}\text { encaja con } V^{6} \\
\text { encaja con } V^{12} \\
\text { encaja con } V^{11} \\
\text { encaja con } V^{7} \\
\text { encaja con } V^{10} \\
\text { encaja con } V^{12} \\
\text { encaja con } V^{12} \\
\text { encaja con } V^{10} \\
\text { encaja con } V^{9}\end{array}$ \\
\hline I.G.469 & To & tendones & $\begin{array}{l}\text { Numerosos tendones } \\
\text { osificados }\end{array}$ & \\
\hline I.G.470 & Co & costillas & 14 costillas (fragmentos) & \\
\hline I.G.471 & Il & ilion & 1 ilion & prepubis izquierdo \\
\hline I.G.472 & $\mathrm{Pu}$ & pubis & 1 pubis & ilion izquierdo \\
\hline I.G.478 & $\mathrm{V}^{6 \mathrm{~s}}$ & $\begin{array}{l}\text { vértebra caudal } \\
\text { [saurópodo] }\end{array}$ & vértebra caudal [saurópodo] & fragmento de sacro \\
\hline I.G.481 partim & $\mathrm{Co}^{\mathrm{s}}$ & costilla [saurópodo] & costilla cervical [saurópodo] & costilla dorsal anterior \\
\hline I.G.481 partim & $\mathrm{Co}^{\mathrm{s}}$ & costilla [saurópodo] & costilla [saurópodo] & costilla dorsal posterior \\
\hline IG.488 & $\mathrm{Is}^{\mathrm{s}}$ & isquion [saurópodo] & isquion [saurópodo] & isquion izquierdo \\
\hline I.G.sin sigla & $X^{s}$ & no aparece & $\begin{array}{l}\text { hueso indeterminado } \\
\text { [saurópodo] }\end{array}$ & $\begin{array}{l}\text { fragmento proximal de } \\
\text { prepubis izquierdo, encaja } \\
\text { con I.G.471 }\end{array}$ \\
\hline
\end{tabular}


Apéndice 2.-Especies de iguanodontoideos descritas en el Cretácico Inferior. Abreviaturas: Fm.: Formación, Gr.: Grupo, il: ilion; is: isquion; Mb.: Miembro, nd: no descrito; pu: pubis.

\begin{tabular}{|c|c|c|c|c|}
\hline Taxón & $\begin{array}{l}\text { Procedencia } \\
\text { del holotipo }\end{array}$ & $\begin{array}{l}\text { Edad } \\
\text { (Formación) }\end{array}$ & $\begin{array}{l}\text { Cadera } \\
\text { conservada }\end{array}$ & Referencias \\
\hline Altirhinus kurzanovi NORMAN 1998 & $\begin{array}{l}\text { Dornogov, } \\
\text { Mongolia }\end{array}$ & $\begin{array}{l}\text { Albiense superior } \\
\text { (Hühteeg Svita) }^{1}\end{array}$ & SI: il, is, pu & $\begin{array}{l}\text { Norman, } 1998 \\
\text { 1: Weishampel et al., } 2004\end{array}$ \\
\hline Barilium dawsoni (LYDEKKER 1888) & $\begin{array}{l}\text { East Sussex, } \\
\text { Inglaterra, R.U. }\end{array}$ & $\begin{array}{l}\text { Valanginiense medio }{ }^{1} \\
\text { (Fm. Wadhurst Clay) }\end{array}$ & SI: il, is, pu & $\begin{array}{l}\text { Norman, } 2010 \\
\text { 1: McDonald } \text { et al., } 2010\end{array}$ \\
\hline $\begin{array}{l}\text { Cedrorestes crichtoni GILPIN, DICROCE } \\
\text { et CARPENTER, } 2007\end{array}$ & Utah, EE.UU. & $\begin{array}{l}\text { Barremiense } \\
\text { (Fm. Cedar Mountain, } \\
\text { Mb. Yellow Cat) }\end{array}$ & SI: il & Gilpin et al., 2007 \\
\hline $\begin{array}{l}\text { Dakotadon lakotaensis (WEISHAMPEL } \\
\left.\text { et } \text { BJORK 1989) (= I. bernissartensis }{ }^{1}\right)\end{array}$ & $\begin{array}{l}\text { Dakota del Sur, } \\
\text { EE.UU. }\end{array}$ & $\begin{array}{l}\text { Barremiense } \\
\text { (Fm. Lakota) }\end{array}$ & NO & $\begin{array}{l}\text { Weishampel \& Bjork, 1989; } \\
\text { Paul, } 2008 \\
\text { 1: Norman, } 1998\end{array}$ \\
\hline Dollodon bambingi PAUL 2008 & $\begin{array}{l}\text { Bernissart, } \\
\text { Hainaut, Bélgica }\end{array}$ & $\begin{array}{l}\text { Barremiense medio- } \\
\text { Aptiense basal } \\
(\text { Fm. Sainte-Barbe })^{1}\end{array}$ & SI: il, is, pu & $\begin{array}{l}\text { Norman, 1986; Paul, } 2008 \\
\text { 1: Yans et al., } 2005\end{array}$ \\
\hline $\begin{array}{l}\text { Eolambia caroljonesa } \\
\text { KIRKLAND } 1998\end{array}$ & Utah, EE.UU. & $\begin{array}{l}\text { Albiense superior- } \\
\text { Cenomaniense inferior } \\
\text { (Fm. Cedar Mountain, } \\
\text { Mb. Mussentuchit) }\end{array}$ & $\begin{array}{l}\text { SI: il, is, } \\
\text { pu-nd }\end{array}$ & $\begin{array}{l}\text { Kirkland, 1998; } \\
\text { Head, } 2001 \\
\text { 1: Maxwell \& Cifelli, } 2002\end{array}$ \\
\hline $\begin{array}{l}\text { Equijubus normani YoU, LUO, SHUBIN, } \\
\text { WITMER, TANG et TANG, 2003b }\end{array}$ & Gansu, China & $\begin{array}{l}\text { Albiense } \\
\text { (Gr. Xinminbao) }\end{array}$ & SI: il-nd & You, 2002; You et al., 2003b \\
\hline $\begin{array}{l}\text { Fukuisaurus tetoriensis KOBAYASHI } \\
\text { et AZUMA } 2003\end{array}$ & Fukui, Japón & $\begin{array}{l}\text { Hauteriviense superior- } \\
\text { Barremiense } \\
\text { (Fm. Kitadani) }\end{array}$ & NO & Kobayashi \& Azuma, 2003 \\
\hline $\begin{array}{l}\text { Hypselospinus fittoni (LYDEKKER } \\
\text { 1889) [incluye I. hollingtoniensis } \\
\text { LYDEKKER 1889] }\end{array}$ & $\begin{array}{l}\text { East Sussex, } \\
\text { Inglaterra, R.U. }\end{array}$ & $\begin{array}{l}\text { Valanginiense medio }{ }^{1} \\
\text { (Fm. Wadhurst Clay) }\end{array}$ & SI: il, is & $\begin{array}{l}\text { Norman, } 2010 \\
\text { 1: McDonald et al., } 2010\end{array}$ \\
\hline Iguanodon anglicus HoLl 1829 & $\begin{array}{l}\text { West Sussex, } \\
\text { Inglaterra, R.U. }\end{array}$ & $\begin{array}{l}\text { Valanginiense medio } \\
\text { (Gr. Hastings Sands, } \\
\text { Fm. Grindstead Clay) }\end{array}$ & NO & Norman, 1987; Paul, 2008 \\
\hline $\begin{array}{l}\text { Iguanodon bernissartensis } \\
\text { BOULENGER } 1881\end{array}$ & $\begin{array}{l}\text { Bernissart, } \\
\text { Hainaut, Bélgica }\end{array}$ & 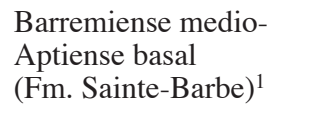 & SI: il, is, pu & $\begin{array}{l}\text { Norman, } 1980 \\
\text { 1: Yans et al., } 2005\end{array}$ \\
\hline $\begin{array}{l}\text { «Iguanodon ottingeri» } \\
\text { GALTON } \text { et JENSEN } 1979\end{array}$ & Utah, EE.UU. & $\begin{array}{l}\text { Albiense inferior }{ }^{1} \\
\text { (Fm. Cedar Mountain) }\end{array}$ & NO & $\begin{array}{l}\text { Galton \& Jensen, } 1979 \\
\text { 1: Scheetz et al., } 2010\end{array}$ \\
\hline $\begin{array}{l}\text { Iguanodon orientalis } \\
\text { ROZHDESTVENSKY } 1952\end{array}$ & $\begin{array}{l}\text { Dornogov, } \\
\text { Mongolia }\end{array}$ & $\begin{array}{l}\text { Albiense superior } \\
\text { (Shinekhudag Svita) }^{1}\end{array}$ & NO & $\begin{array}{l}\text { Norman, } 1996 \\
\text { 1: Weishampel et al., } 2004\end{array}$ \\
\hline Jintasaurus meniscus You et Li 2009 & Gansu, China & $\begin{array}{l}\text { Albiense } \\
\text { (Gr. Xinminpu) }\end{array}$ & NO & You \& Li, 2009 \\
\hline Jinzhousaurus yangi WANG et XU 2001 & Liaoning, China & $\begin{array}{l}\text { Hauteriviense- } \\
\text { Barremiense } \\
\text { (Fm. Yixian) }\end{array}$ & SI, nd & Wang \& Xu, 2001 \\
\hline $\begin{array}{l}\text { Kukufeldia tilgatensis MCDONALD, } \\
\text { BARRETT et CHAPMAN } 2010\end{array}$ & $\begin{array}{l}\text { West Sussex, } \\
\text { Inglaterra, R.U. }\end{array}$ & $\begin{array}{l}\text { Valanginiense medio- } \\
\text { superior (Fm. Tunbridge } \\
\text { Wells Sand, Mb. } \\
\text { Grinstead Clay) }\end{array}$ & NO & McDonald et al., 2010 \\
\hline
\end{tabular}


Apéndice 2 (continuación).-Especies de iguanodontoideos descritas en el Cretácico Inferior. Abreviaturas: Fm.: Formación, Gr.: Grupo, il: ilion; is: isquion; Mb.: Miembro, nd: no descrito; pu: pubis.

\begin{tabular}{|c|c|c|c|c|}
\hline Taxón & $\begin{array}{l}\text { Procedencia } \\
\text { del holotipo }\end{array}$ & $\begin{array}{l}\text { Edad } \\
\text { (Formación) }\end{array}$ & $\begin{array}{l}\text { Cadera } \\
\text { conservada }\end{array}$ & Referencias \\
\hline $\begin{array}{l}\text { Lanzhousaurus magnidens } \\
\text { You, Ji et Li } 2005\end{array}$ & Gansu, China & $\begin{array}{l}\text { Cretácico Inferior } \\
\text { (Gr. Hekou) }\end{array}$ & SI: pu & You et al., 2005 \\
\hline $\begin{array}{l}\text { Lurdusaurus arenatus TAQUET } \\
\text { et RUSSEL } 1999 \text { (= «Gravisaurus } \\
\text { tenerensis })\end{array}$ & Níger & $\begin{array}{l}\text { Aptiense } \\
\text { (Fm. Elrhaz) }\end{array}$ & SI: il, is, pu & $\begin{array}{l}\text { Chabli, 1988; Taquet \& } \\
\text { Russel, } 1999\end{array}$ \\
\hline $\begin{array}{l}\text { «Mandschurosaurus» laosensis } \\
\text { HOFFET 1944a }\end{array}$ & Laos & $\begin{array}{l}\text { Aptiense-Albiense } \\
(\text { Fm. Grès supérieurs })^{1}\end{array}$ & SI: il & $\begin{array}{l}\text { Hoffet, 1944a } \\
\text { 1: Weishampel et al., } 2004\end{array}$ \\
\hline $\begin{array}{l}\text { Mantellisaurus atherfieldensis } \\
\text { (HoOLEY 1925) }\end{array}$ & $\begin{array}{l}\text { Isle of Wight, } \\
\text { Inglaterra, R.U. }\end{array}$ & $\begin{array}{l}\text { Aptiense inferior } \\
\text { (Fm. Upper Vectis) }\end{array}$ & SI: il, is, pu & $\begin{array}{l}\text { Norman, 1986; Paul, 2007, } \\
2008\end{array}$ \\
\hline $\begin{array}{l}\text { Muttaburrasaurus langdoni } \\
\text { BARTHOLOMAI et MOLNAR } 1981\end{array}$ & $\begin{array}{l}\text { Queensland, } \\
\text { Australia }\end{array}$ & $\begin{array}{l}\text { Albiense } \\
\text { (Fm. Mackunda) }\end{array}$ & SI: il, is, pu & $\begin{array}{l}\text { Bartholomai \& Molnar, } \\
\text { 1981; Molnar, } 1996\end{array}$ \\
\hline $\begin{array}{l}\text { Nanyangosaurus zhugeii Xu, ZHAO, } \\
\text { LU, HuANG, LI et DONG, } 2000\end{array}$ & Henan, China & $\begin{array}{l}\text { Cretácico Inferior } \\
\text { (Fm. Sangping) }\end{array}$ & SI: is & Xu et al., 2000 \\
\hline Ouranosaurus nigeriesis TAQUET 1976 & Níger & Aptiense (Fm. Elrhaz) & SI: il, is, pu & Taquet, 1976 \\
\hline Owenodon hoggii (OwEN 1874) & $\begin{array}{l}\text { Dorset, } \\
\text { Inglaterra, R.U. }\end{array}$ & $\begin{array}{l}\text { Berriasiense medio } \\
\text { (Fm. Purbeck Limestone } \\
\text { =Fm. Durlston) }\end{array}$ & NO & Galton, 2009 \\
\hline $\begin{array}{l}\text { Penelopognathus weishampeli } \\
\text { GODEFROIT, Li et SHANG } 2005\end{array}$ & $\begin{array}{l}\text { Mongolia } \\
\text { Interior, China }\end{array}$ & $\begin{array}{l}\text { Albiense } \\
(\text { Fm. Bayan Gobi) }\end{array}$ & NO & Godefroit et al., 2005 \\
\hline Planicoxa depressa (GILMORE 1909) & $\begin{array}{l}\text { Dakota del Sur, } \\
\text { EE.UU. }\end{array}$ & $\begin{array}{l}\text { Barremiense } \\
\text { (Fm. Lakota) }\end{array}$ & SI: il, pu & $\begin{array}{l}\text { Gilmore, 1909; Weishampel } \\
\text { \& Bjork, 1989; Carpenter \& } \\
\text { Wilson, } 2008\end{array}$ \\
\hline $\begin{array}{l}\text { Planicoxa venenica DiCROCE } \\
\text { et CARPENTER } 2001\end{array}$ & Utah, EE.UU. & $\begin{array}{l}\text { Aptiense-Albiense } \\
\text { (Fm. Cedar Mountain, } \\
\text { Mb. Poison Strip) }\end{array}$ & SI: il & DiCroce \& Carpenter, 2001 \\
\hline $\begin{array}{l}\text { Probactrosaurus gobiensis } \\
\text { ROZHDESTVENSKY } 1966 \text { (= P. } \\
\text { alashanicus ROZHDESTVENSKY 1966) }\end{array}$ & $\begin{array}{l}\text { Mongolia } \\
\text { Interior, China }\end{array}$ & $\begin{array}{l}\text { Barremiense } \\
(\text { Fm. Dashuiguo })^{1}\end{array}$ & SI: il, is, pu & $\begin{array}{l}\text { Norman, } 2002 \\
\text { 1: Itterbeeck et al., } 2004\end{array}$ \\
\hline $\begin{array}{l}\text { «Probactrosaurus» mazongshanensis } \\
\text { LU } 1997\end{array}$ & Gansu, China & $\begin{array}{l}\text { Albiense } \\
(\text { Gr. Xinminbao })^{1}\end{array}$ & SI: il-nd, pu & $\begin{array}{l}\text { Lu, } 1997 \\
\text { 1: Tang et al., } 2001\end{array}$ \\
\hline $\begin{array}{l}\text { Theiophytalia kerri BRILL } \\
\text { et CARPENTER } 2007\end{array}$ & $\begin{array}{l}\text { Colorado, } \\
\text { EE.UU. }\end{array}$ & $\begin{array}{l}\text { Aptiense-Albiense (Fm. } \\
\text { Purgatoire, Mb. Lytle) }\end{array}$ & NO & Brill \& Carpenter, 2007 \\
\hline $\begin{array}{l}\text { Vectisaurus valdensis HULKE } 1879 \\
\text { (=Iguanodon atherfieldensis }{ }^{1} \\
=\text { Mantellisaurus } \mathrm{sp}^{2} \text { ) }\end{array}$ & $\begin{array}{l}\text { Isle of Wight, } \\
\text { Inglaterra, R.U. }\end{array}$ & $\begin{array}{l}\text { Barremiense superior } \\
(\text { Fm. Wessex })^{2}\end{array}$ & SI: il & $\begin{array}{l}\text { Galton, } 1976 \\
\text { 1: Norman, 1990, } 2004 \\
\text { 2: Paul, } 2008\end{array}$ \\
\hline
\end{tabular}

